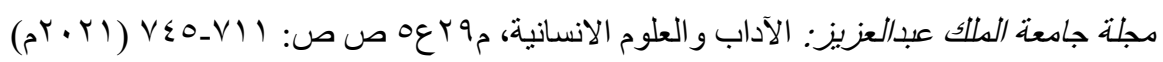

$$
\begin{aligned}
& \text { DOI:10.4197/Art.29-5.24 }
\end{aligned}
$$

\title{
الخصائص الجغرافية للمقاهي النسائية بمدينة خميس مشيط (دراسة في الجغرافية الاقتصادية)
}

\author{
حنان عبد الهادي سعيد القاضي القحطاني

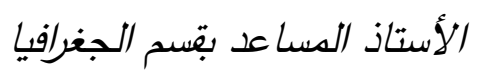 \\ كلية العلوم الإنسانية \\ جامعة الملك خالد - أبها
}

مستخلص. اهتمت هذه الدراسة بالخصائص الجغرافية للمقاهي النسائية بمدينة خميس مشيط ، حيث اعتمد البحث

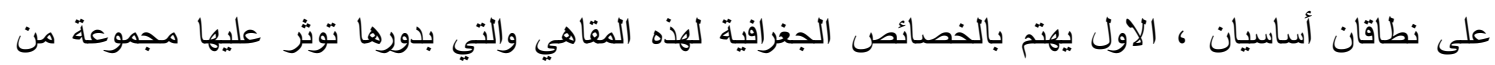

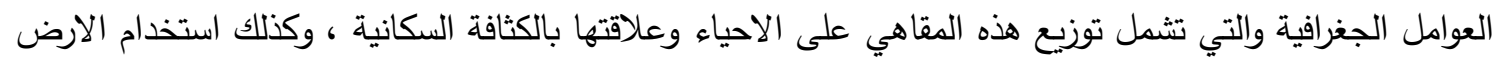

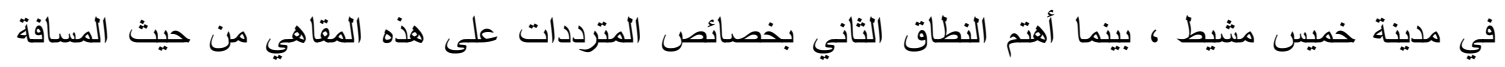

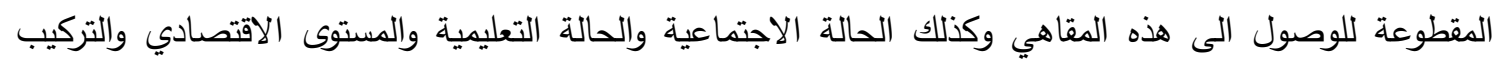

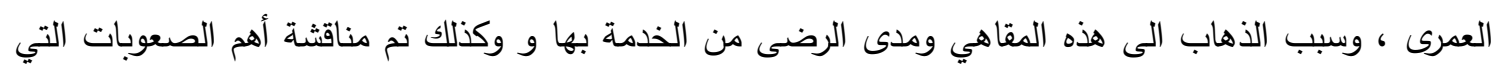

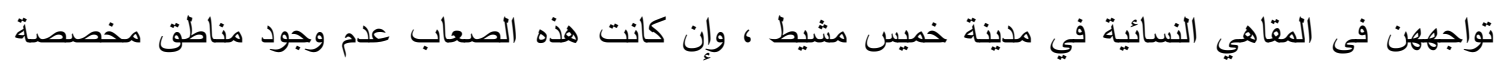

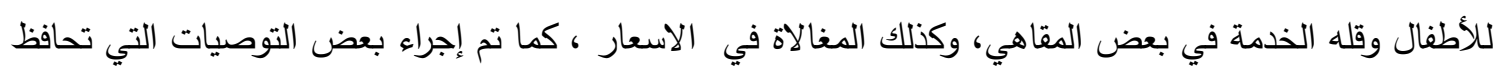

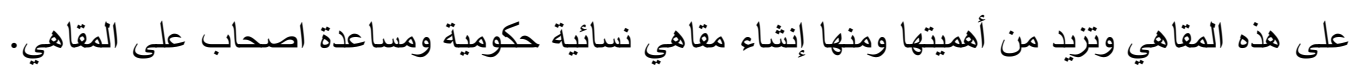

التى تأخذ الطابع الرسمى ، ويمكن أن يكون لهذه المقدمة

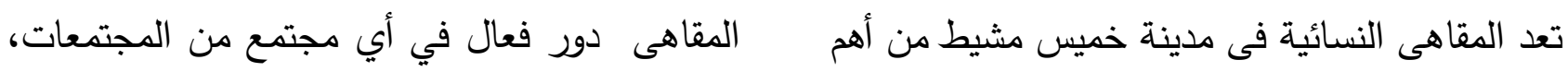

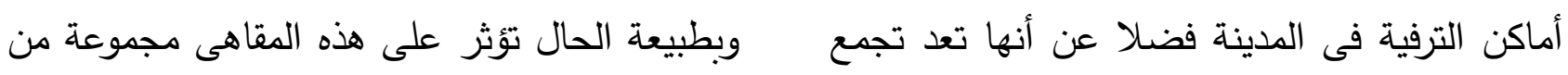

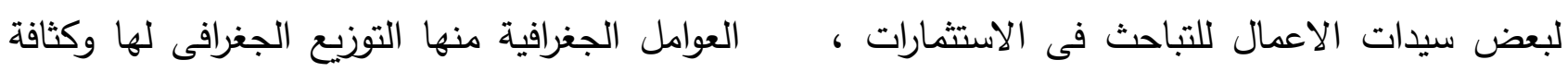

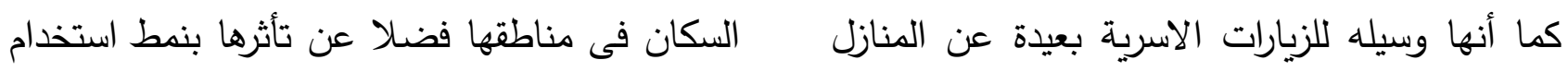


r- أهداف الدراسة: كان الهدف الرئيس من هذه

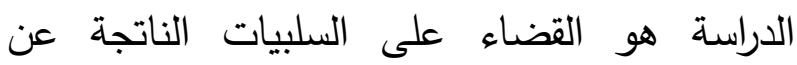
المقاهى النسائية وتعظيم اوجه الاستفادة منها من

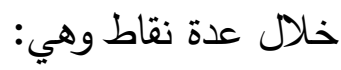
- التطور التاريخى للمقاهى - دراسة التقسيم الادراى والسكانى فى مدينة خميس مشيط - التوزيع الجغرافى للمقاهى النسائية فى مدينة خميس مشيط - الخصائص الجغرافية للمترددات على المقاهى ميطى النسائية ع- منهجية الاراسة: تم الاعتماد على مجموعة من المناهج التى تخدم اهداف البحث وهي: المنهج التاريخي: وتتاول التطور التاريخي للمقاهي المنهج التحليلي: وفى هذا المنهج تم الاهتمام بتحليل الخرائط والجداول محل الدراسة فضلا عن تحليل استمارات الاستبيان. التطور التاريخى للمقاهى: ظهرت اقدم المقاهى فى العالم فى مدينة دمشق عام . r آ ا تم افتتاح أوّل مقهى في اسطنبول، بينما

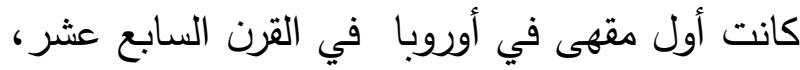
وحيث وُجدت المقاهي تزداد شعبيّتها بسرعة، بينما كانت أول مقهى في أوروبا الغربية فى البندقية عام 9 צ7 ا، بسبب نشاط التجارة والشحن ، وكانت أوّل

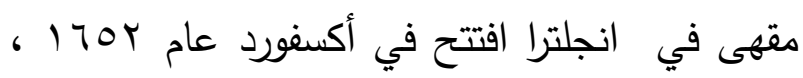

الارض لمناطق الجوار لها ، ويتاول هذا البحث هذه العوامل وكذلك خصائص المترددات على هذه المقاهى من حيث المسافة التى تقطعها وإمكانية الوصول ومدى الرضا عن الخدمات التى تقدمها هذه المقاهى ، وكذلك المستوى الاقتصادى والحاله الاجتماعية والحاله التعليمية وجنسية المترددات وكذلك الصعوبات التى تواجه المترددات على هذه المقاهى ، وسوف تعتمد الباحثة على أسلوب العينة

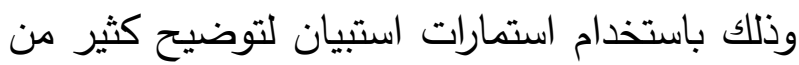

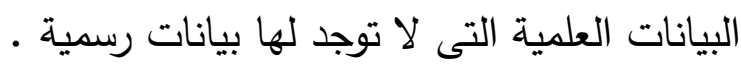

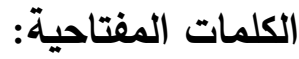
المقاهى النسائية، استخدام الارض، المستوى الاقتصادي، الحالة التعليمية، الحالة الاجتماعية 1- مشكلة الدراسة: تناقش هذه الدراسة دور المقاهى النسابية فى تتمية العلاقات الاسرية والاقتصادية فضلا عن تحليل الخصائص السكانية لمرتادي هذه المقاهي. r- أهمية الدراسة: تعد مدينة خميس مشيط من المدن ذات الرواج التجاري والاقتصادي الكبير والذي انعكس على ظهور خدمات ترفيهية قيمة ومنها المقاهى النسائية والتى يمكن ان تلعب دورا كبيرا فى عدة مجالات وخاصة المجالات الاجتماعية والاقتصادية وذالك من خلال تتلاشى سلبيات هذه المقاهى مع تعظيم الايجابيات التى يمكن ان تظهر من خلال تحليل هذا البحث. 
المملكة كافة ،كما يقدَّر حجم الطلب على خدمات المقاهي أو الكافيهات بالمملكة بنحو ، . . ألف فرد، منها نحو . . ألف فرد بالرياض وحدها. أما أحدث الكافيهات السعودية فهي انتشار الكافيهات النسائية التي باتت مقرًا لتجمعات الفئات المنسجمة من أن النساء، سواء شابات أو سيدات، وأحيانًا أخرى هعراء تجمعهن مهنة أو هواية أو تخصص، فقد انتشرت هذه الكافيهات داخل المشاغل أو النوادي أو غيرها ويتوقع أن تزايد عدد هذه الكافيهات بقوة مستقبلاً، خاصة داخل النوادي النسائية أو الرياضية أو حتى داخل المستشفيات ( http://www.aleqt.com ) العلاقات المكانية ومنطقة الدراسة: تعتبر مدينة خميس مشيط من أهم وأكبر التجمعات العمرانية بمنطقة عسير، حيث تقع في متسع من الأرض عند إنتهاء السلاسل الجبلية وعلي مجري وادي بيشة، ووادي عتود مما يسر الوصول إليها وإتصالها بالمناطق الأخرى، فإختارتها القوافل القديمة لتكون محطة علي الطرق، وصارت مركزاً لطرق المواصلات الرئيسية حيث تقع مدينة خميس مشيط داخل نطاق محافظة خميس مشيط الواقعة ضمن إمارة منطقة عسير في جنوب غرب المملكة العربية السعودية شكل (1). وتعتبر مدينة خميس مشيط من المدن الرئيسية في جنوب المملكة العربية السعودية ، وتعد العاصمة الاقتصادية لمنطقة عسير

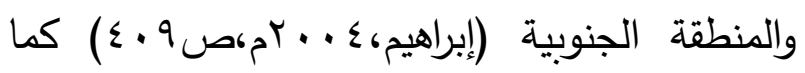
إنها من اكبر التجمعات العمرانية في جنوب غرب
وفى امريكا كانت اول مقهى على أراضيها في بوسطن عام IVT IVT وكانت أوّل (مقهى) في ثيينًا تأسّس عام برا ا من قبل مقيم يولندي، جرجي فرانشيجاك كُلجتسكي ، وفى الترن الثامن عشر انتشرت شعبية القهوة في عموم الأراضي الالمانية ، وبدأت ترتقي إلى عادات الطبقات الحاكمة وبصفة عامة يمكن القول انه انتشرت القهوة وثقافة شربها في جميع أرجاء العالم مع النصف الثاني من القرن الثامن عشر (https://albukhari.com) ( المقاهى فى المملكة العربية السعودية : تتواجد المقاهى فى المملكة العربية السعودية حسب

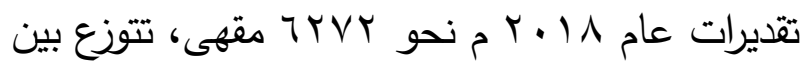
المقاهي العادية أو الشعبية وأخرى كافيهات عصرية من الطراز الحديث ، وحسب آخر تقديرات منشورة، فإن الرياض، يليها مكة المكرمة، ثم المنقطة الشرقية، تمتلك أكبر عدد من المقاهي، إلا أن المقاهي الغربية تتركز بمدينة جدة ، ويوجد نوعان من المقاهي الآن: مقاهي البيع السريع، وهي التي تمتلك خطوطًا للبيع فقط، ولا يوجد مقاعد للجلوس عليها، وهو نمط المحال أو الأكشاك، خاصة في طرق الهاي واي التي تبيع أكواب القهوة والثاي دونما انتظار جلوس المرتادين ، وفي المقابل توجد مقاهي الجلوس في الثوارع الحيوية التي ترغِّب مرتاديها للجلوس في مناطق بعينها أو مولات أو مناطق هادئة ، ويقدر عدد مقاعد المقاهي بالمملكة حاليًا بنحو .ا ألف مقعد، تتوزع على مدن 


$$
\text { حنان عبد الهادي سعيد القاضي القحطاني }
$$

المملكة ، ومما زاد من أهمية مدينة خميس مشيطومن الجنوب محافظة احد رفيدة ومن الغرب يحدها نشأتها علي ضفاف مجري وادي بيشة حيث نطاق أبها ، وتحتل مدينة خميس مشيط المكانة

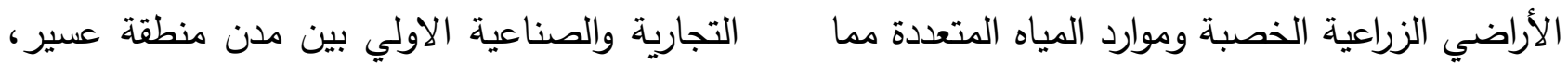

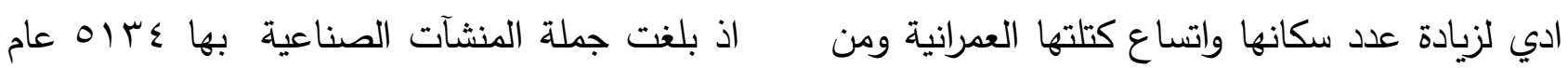

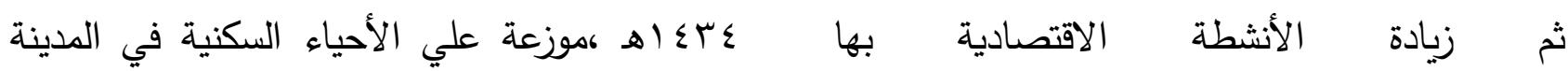

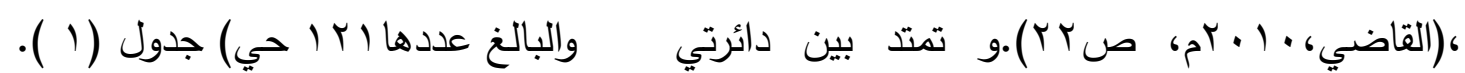
عرض (1) وخطي طول ( شرقاً ، ويحدها من ناحية الشمال محافظتي تثليث

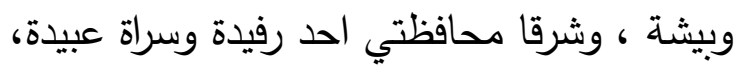

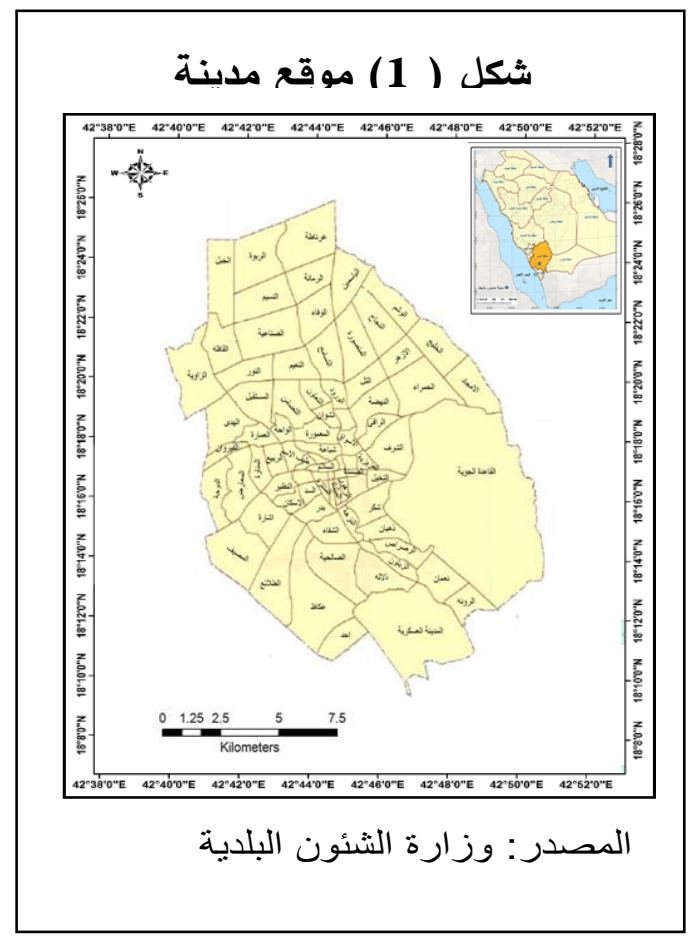

أولا: التقيم الادارى لأحياء مدينة خميس مشيط وعدد السكان: أ مكن تقسيم احياء منطقة الدراسة الى عدة قطاعات كما يتضح من جدول ( () وشكل (r) 


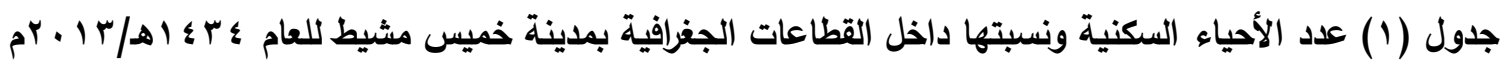

\begin{tabular}{|c|c|c|c|c|c|}
\hline$\%$ & المساحة & $\%$ & عدد الاحياء السكنية & القطاعات & 5 \\
\hline$r V, \varepsilon$ & $|r r, q|$ & 17,0 & $r \cdot$ & القطاع الشمالي الشرقي & 1 \\
\hline$\lceil\wedge\rceil$, & IAV,or & Tr, & rq & القطاع الشمالي الغربي & r \\
\hline 19,7 & $9 \varepsilon, 9 \vee$ & 17,0 & $r$. & القطاع الجنوبي الشرقي & r \\
\hline $1 \leq, \varepsilon$ & $V \cdot, 10$ & $r \leqslant, v$ & $\leqslant r$ & القطاع الجنوبي الغربي & $\varepsilon$ \\
\hline $1 \ldots$ & $\sum \wedge 0,07$ & $1 \ldots$ & $|r|$ & جملة القطاعات & \\
\hline
\end{tabular}

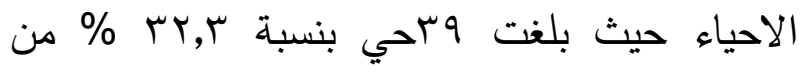
جملة الاحياء في منطقة الدراسة واحتل الترتيب

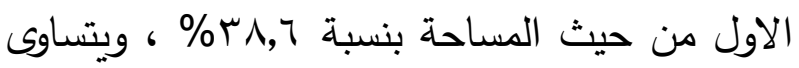
كل من القطاعين الثمالي الثرقي والجنوبي الغربي

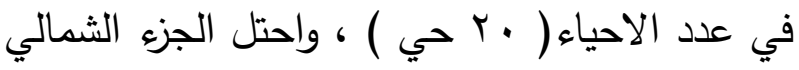

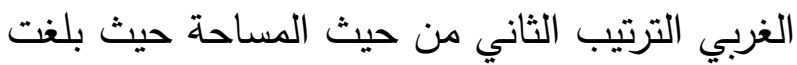

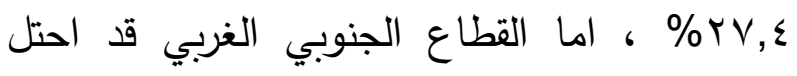

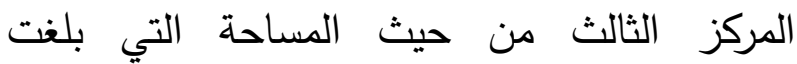
19,7 \% \% . وبداسة توزيع السكان داخل احياء مدينة

خميس مشيط كما يتضح من شكل ( r ) ).
المصدر : من اعداد الباحثة اعتمادا علي بيانات وزارة

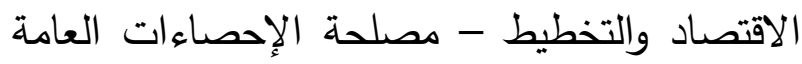

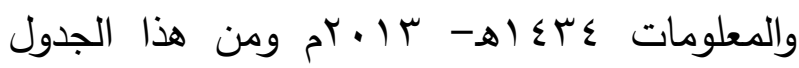
يتضح ان عدد الاحياء السكنية في مدينة خميس

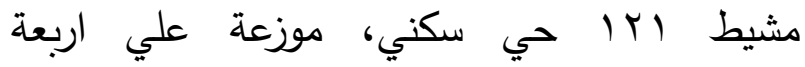
قطاعات جغرافية يتصدر القطاع الجنوبي الثرقي

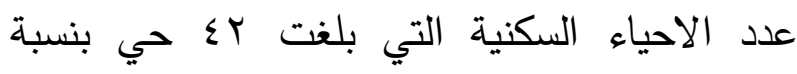

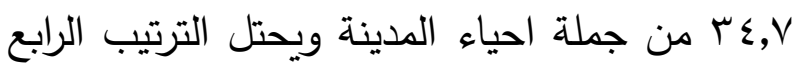

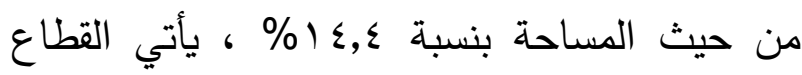

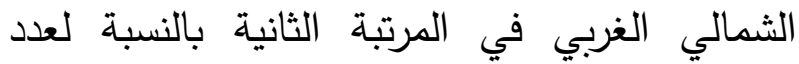

شكل (r) التقسيم الإدارى لمدينة خميس مشيط

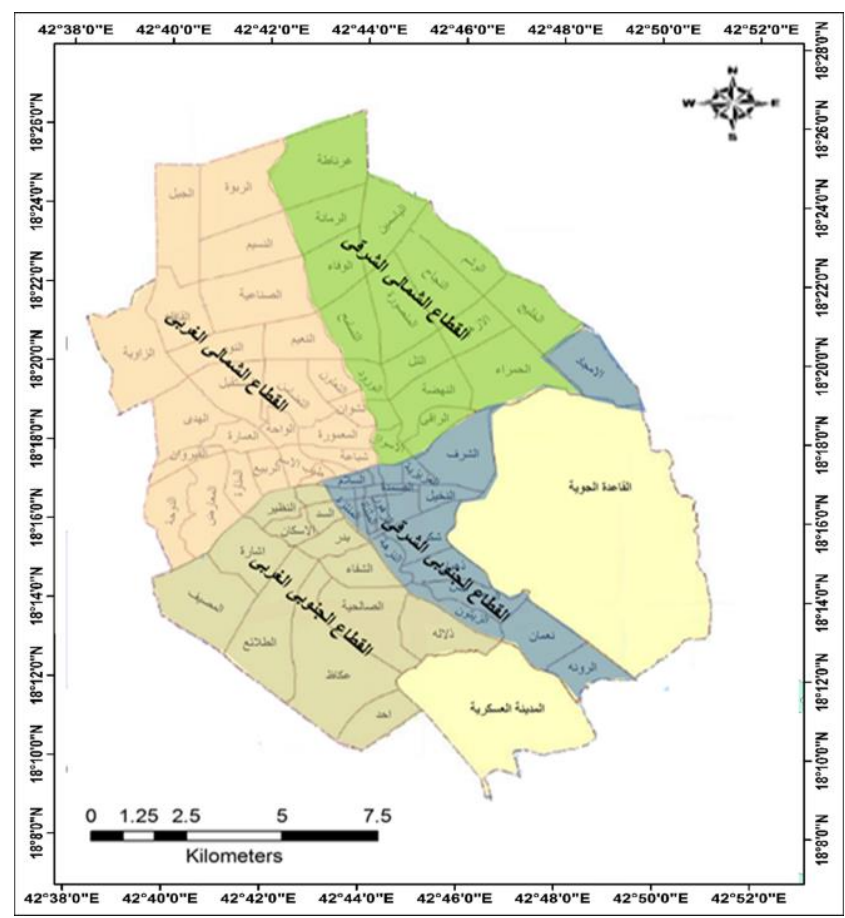

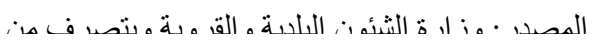




$$
\text { حنان عبد الهادي سعيد القاضي القحطاني }
$$

شكل ( r ) اعداد السكان على مستوى احياء مدينة خميس مشيط

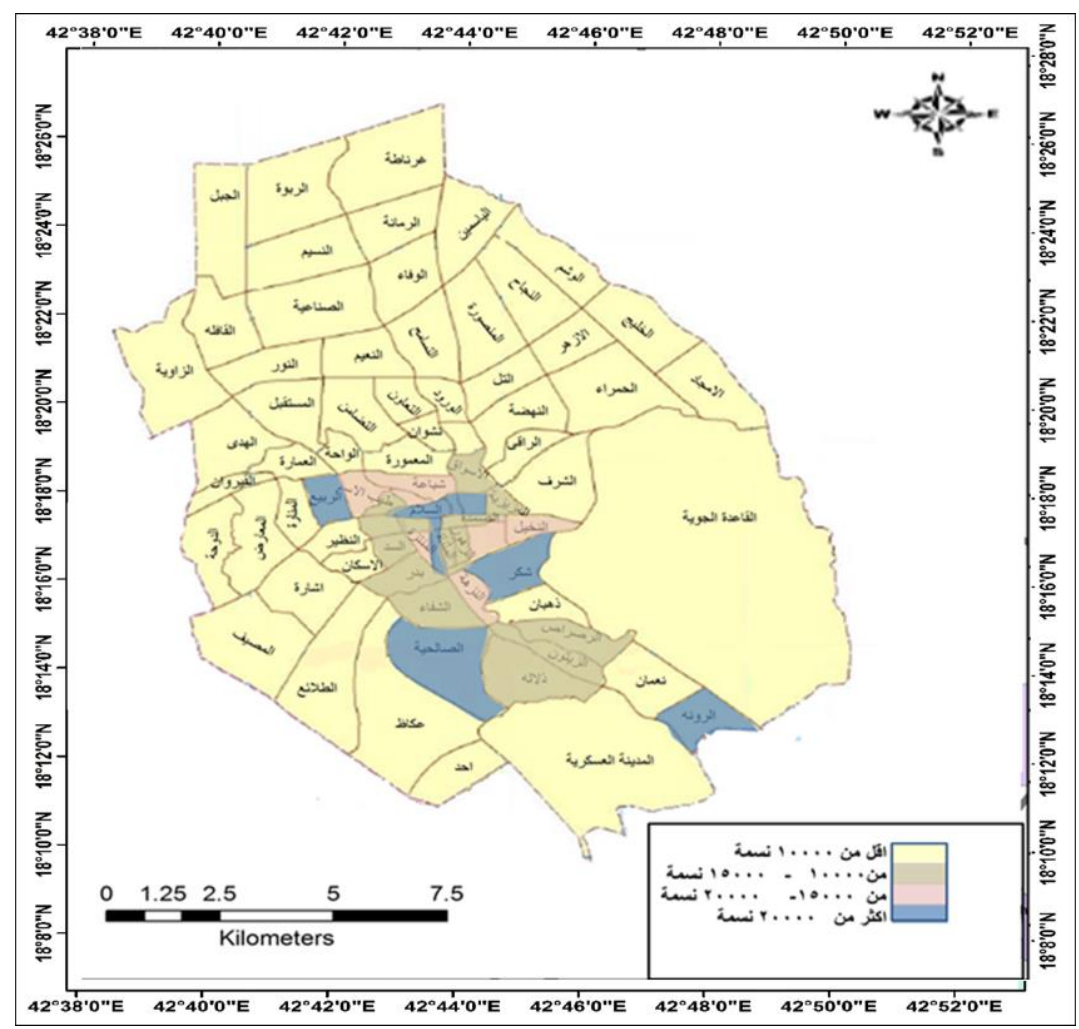

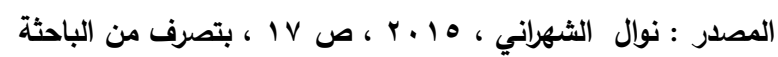

و يتضح ان اكثر الاحياء سكانا هى احياء السلام المدينة يقل عدد السكان بها عن • الاف نسمة

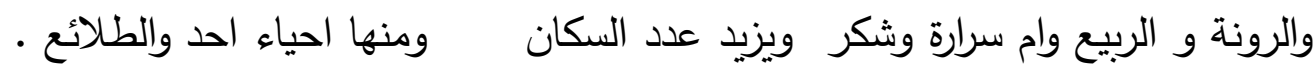
بها عن • ب الف نسمة ويلاحظ انها منطقة المركز ثانيا : التوزيع الجغرافى للمقاهى النسائية محل فى المدينة بينما جات مراكز اخرى فى فئة متوسطة الدراسة فى مدينة خميس مشيط فى عدد السكان والتى تتراوح فيها عدد السكان ما تعد دراسة نفوذ الخدمة من صميم عمل الجغرافى لما بين 10 و • r الف نسمة ومنها احياء طيب الاسم يقوم به بالربط بين عدد المستفيدين من الخدمة والتخيل والمنتزة وكان من الفئة الاقل فى عدد والمسافة المقطوعة ، ويقييم مدى أهمية الخدمة السكان التى تتراوح بين · ا وها الف نسمة احياء وملاءمة موقعها كي تؤدى وظيفتها على الوجه

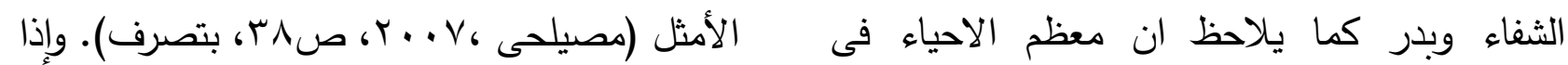
كانت الجغرافية تهتم بدراسة العلاقة بين السكان 
والموارد الطبيعية هوما يعرف بالاتجاه الايكولوجى المترددات على المقاهي النسائية في مدينة خميس للجغرافية مشيط من احياء مختلفة بقدر الامكان وذلك كما 14 حيث تم اختيار عينة البحث عشوائيا من يتضح من شكل (ع). شكل (؛) توزيع المقاهى النسائية المدروسة على مستوى احياء مدينة خميس مشيط

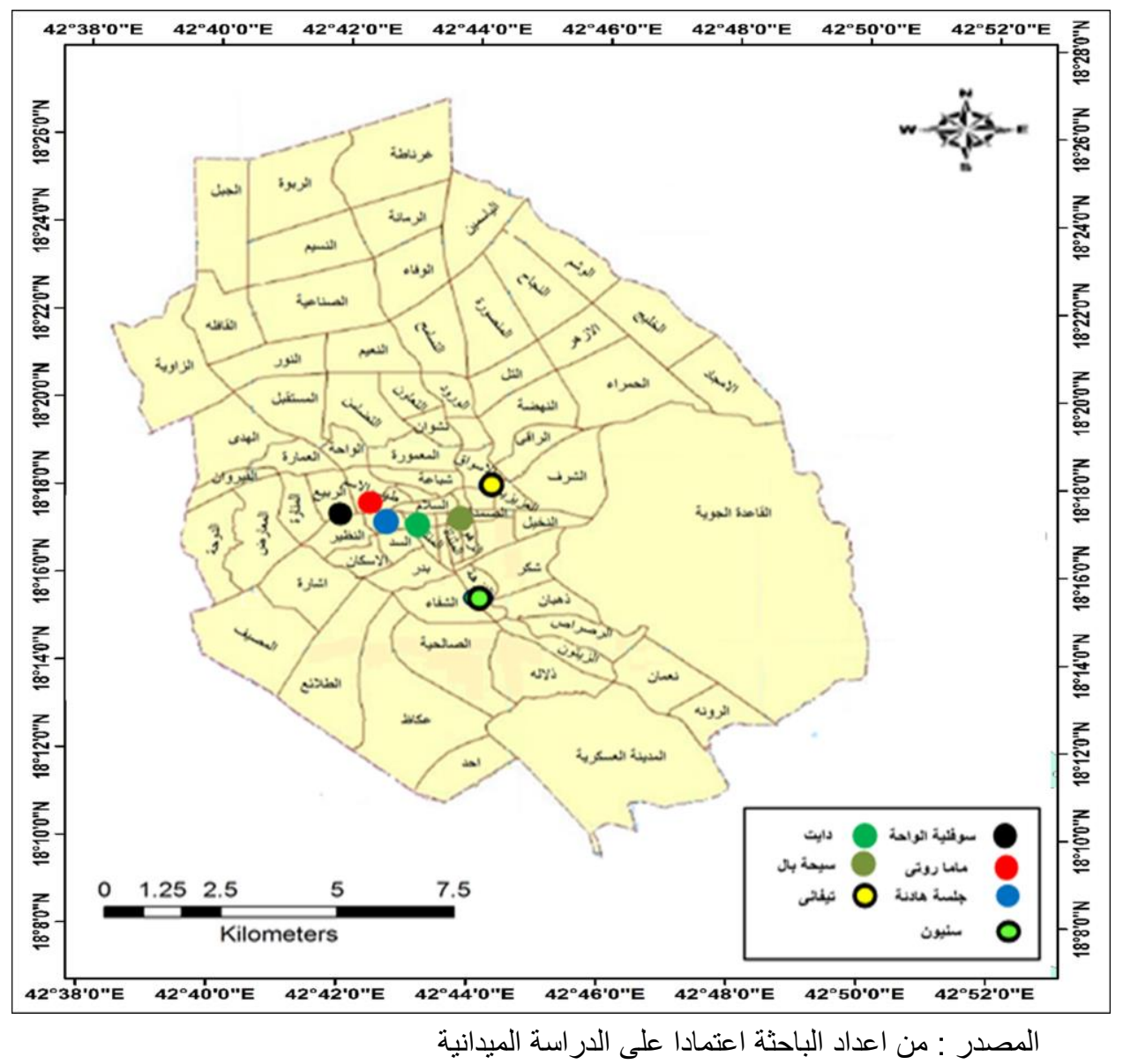

من الشكل السابق يتضح توزع المقاهى النسائية ذات الكثافة السكانية العالية التى تساعد على المدروسة على احياء وسط المدينة وهى حى الراقى عمليات الربح من خلال هذا المشروع ويمكن ايجاد والضيافة والرصراص والدرب والمعارض والحربى العلاقة بين توزيع المقاهى النسائية وكثافة السكان والحضارى وبدراسة العلاقة بين توزيع السكان على فى احياء مدينة خميس مشيط كما يتضح من شكل

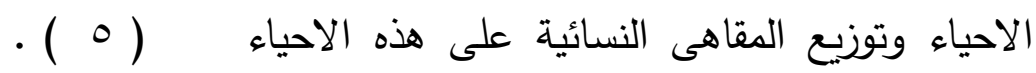
حيث يلاحظ تركز معظم المقاهى فى مركز المدينة 
شكل (0 ) العلاقة بين التوزيع الجغرافى للمقاهى النسائية المدروسة وتوزيع عدد السكان على

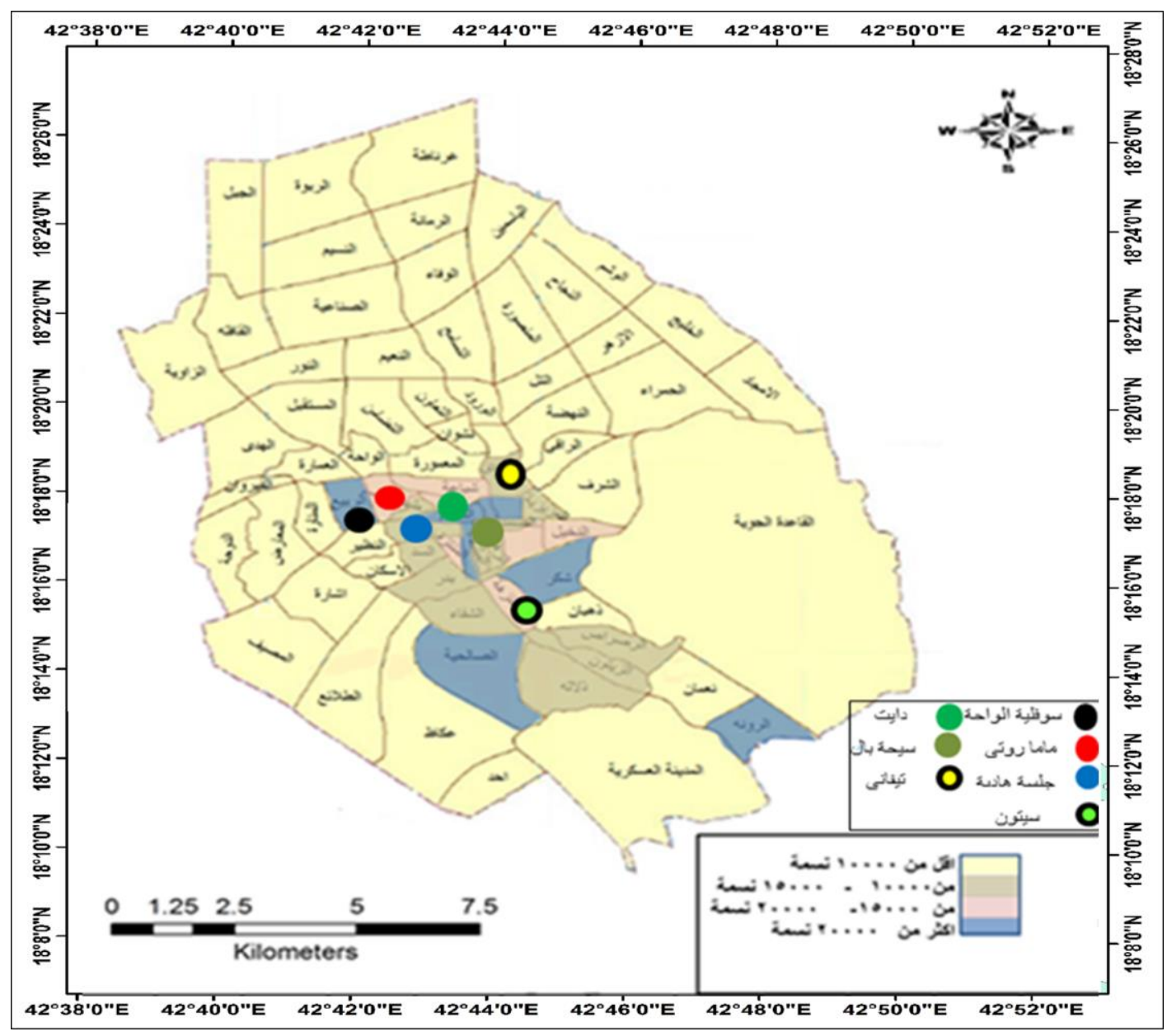

المصدر : من عمل الباحثة اعتمادا على شكلى ؟ و ه

وبدراسة العلاقة بين استخدام الارض فى المدينة الأرض ، الماء ، الهواء ) ، بحيث يعس لنا

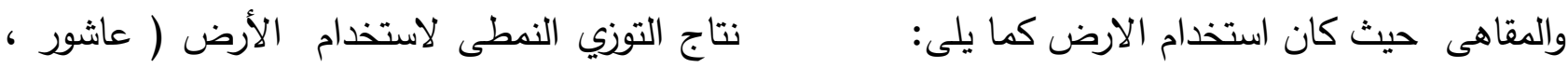

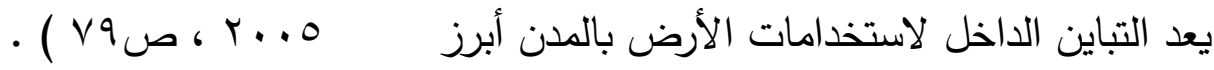
خصائص تحضرها في العصر الحديث ؛ فهى صورة لأنشطة الإنسان على الأرض ودلالة على تفاعل ديناميكى بين أربعة متغيراًت ( الإنسان 


\section{شكل († ) انماط استخدام الارض فى مدينة خميس مشيط}

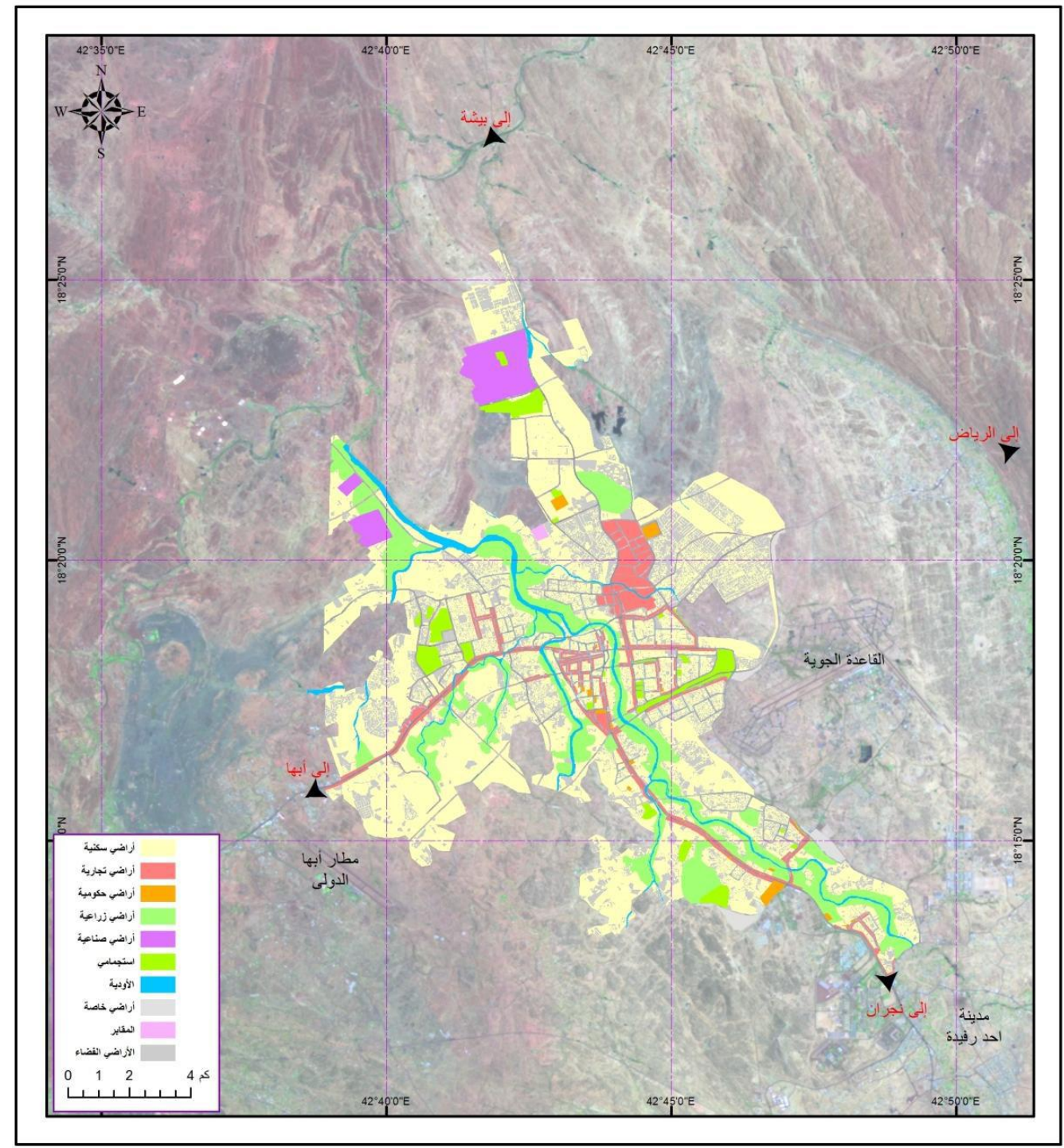

المصدر : نوال الثهر اني، 10 • ، ، ص بr 


$$
\text { حنان عبد الهادي سعيد القاضي القحطاني }
$$

جدول رقم ( r ) استخدامات الاراضى بمدينة خميس مشيط عام q ؟ ؛ اهـ

\begin{tabular}{|c|c|c|}
\hline \multicolumn{2}{|c|}{ عام هب ؛ أهـ } & \multirow[t]{2}{*}{ الاستخدام } \\
\hline النسبة (\%) & المساحة (مץY) & \\
\hline$\varepsilon, \vee \wedge \uparrow$ & YYO1. ETV & سكنى \\
\hline$\cdot, Y 91$ & $1 r v \cdot v \varepsilon r$ & سكنى تجارى \\
\hline$\cdot, \cdot r$ & 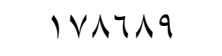 & سكنى مختلط \\
\hline $1,19 \varepsilon$ & OT) & تجارى \\
\hline $0,7 \leq$. & TTOTMYTE & اراضى زراعية ومزارع \\
\hline$\cdot, \leqslant 01$ & YITH.VE & صناعى \\
\hline$\cdot, \cdot T \varepsilon$ & r...117 & حرفى \\
\hline$\cdot, \cdots 9$ & $\leq \leqslant 7 \%$. & مواقع سياحية واثرية \\
\hline$\cdot, 1 \cdot 7$ & $\varepsilon q \vee \wedge \cdot 1$ & خدمات ترفيهية \\
\hline$\cdot, \cdot r q$ & $1 \wedge \leq \wedge \wedge \vee$ & خدمات رباضية \\
\hline • & $101000 \leqslant$ & خدمات تعليمية \\
\hline$\cdot, 1 \cdot 7$ & 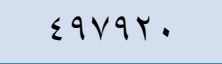 & خدمات صحية \\
\hline$\cdot, r \cdot V$ & $9 Y Y 100$ & خدمات دينية \\
\hline$\cdot, \cdot 1 \leq$ & $7799 V$ & خدمات ثقافية \\
\hline$\cdot, \wedge$ & TrVVqV & خدمات اجتماعية \\
\hline$\cdot, .90$ & $\Sigma \Sigma \vee \wedge \Sigma Y$ & خدمات حكومية وامنية \\
\hline$\cdot, \ldots$ & rYAVA & خدمات الاتصالات \\
\hline$\cdot, \ldots r$ & $\lambda r \leqslant \varepsilon$ & خدمات البلدية \\
\hline or,quv & rorytVris & اراضى فضاء \\
\hline$\cdot, \leqslant 9 \leqslant$ & TrYוT & اراضى صحراوية غير منماة \\
\hline$\Lambda, Y Y \varepsilon$ & rNTV7017 & مناطق جبلية \\
\hline$\cdot, O \wedge r$ & 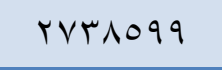 & اودية ومخرات سيول \\
\hline $1 T, .00$ & $07794.0 \leq$ & مناطق عسكرية \\
\hline$\cdot, r \cdot r$ & $9 \leq \wedge q \cdot V$ & مقابر \\
\hline$\cdot, r \leq 1$ & $11 \pi \leqslant \vee 97$ & انتظار سيارات \\
\hline $1 \cdot, \pi \mid r$ & $\{99 \cdot \wedge \wedge 1)$ & الطرق \\
\hline
\end{tabular}




\begin{tabular}{|c|c|c|}
\hline צואו, & $09 . \leq r \wedge$ & محطات مياة وخزانات \\
\hline., .01 & (YVI.91 & محطات الصرف الصحى \\
\hline$\cdot, \cdot r \cdot$ & 97YTO & محطات الكهرباء \\
\hline $1 \cdots, 11$ & $\varepsilon V \cdot r \cdot 0.7 q$ & الاجمالي \\
\hline
\end{tabular}

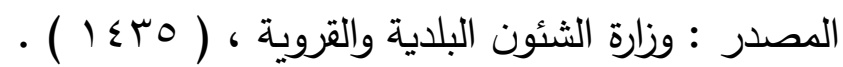

يتضح من جدول (Y) وشكل (T) تفاوت نسب مركز المدينة وبالتالى كان تركز المقاهى فى تلك

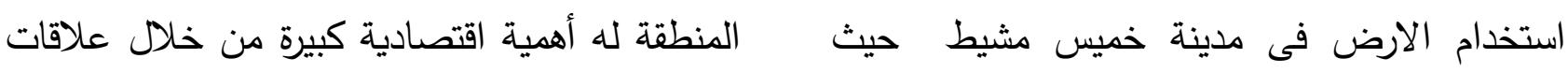
بلغت نسبة الاستخدام السكنى الى نحو 9 , 1 \% من الجوار مع الخدمات التجارية والسياحية والصناعية

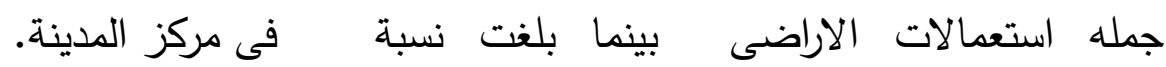

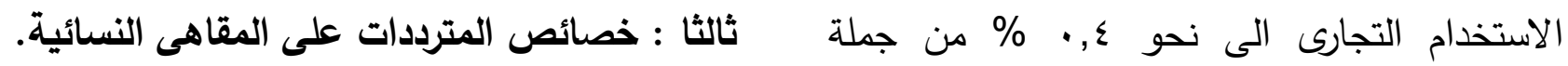
استعمالات الاراضى ، فى حين بلغ نسبة الاستخدام من خلال عمل زيارات في مواعيد مختلفة لسبعة

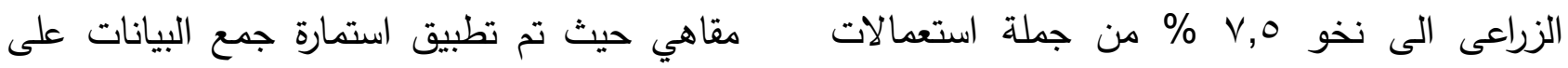

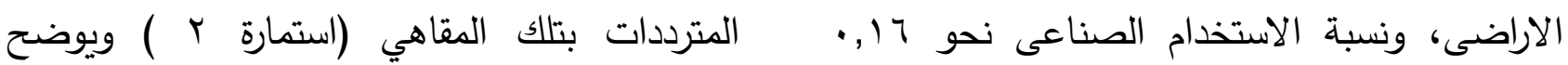
\% من جملة استعمالات الاراضى بينما كانت اعلى الجدول التالي وصف لعينة البحث وفقا للعدد الذي التي النسب لارضى الفضاء بنسبة r7 \% و وان تتوعت تم التطبيق عليه بكل مقهى • باقى النسب بين الطرق والخدمات العامة والخدمات

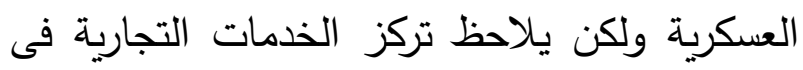

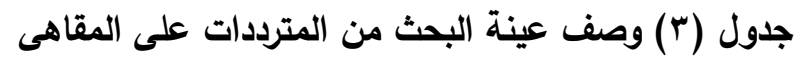

\begin{tabular}{|c|c|c|}
\hline النسبة المئوية & عدد المرتادت المطبق عليهن & اسم المقهى \\
\hline$I V, r$ & $r$. & تيفاني \\
\hline$I V, r$ & r. & جلسة هادئة \\
\hline 11,0 & $r$. & دايت كوفي \\
\hline $1 Y, 7$ & rr & سنيون \\
\hline$V, r$ & r. & سوفليه الواحة \\
\hline $1 Y, T$ & rt & سيحة بال \\
\hline 11,0 & r. & ماما روتى \\
\hline$\% 1 .$. & IV $\varepsilon$ & الإجمالي \\
\hline
\end{tabular}

المصدر : من عمل الباحثة اعتمادا على تحليل استمارات الاستبيان. 
واهتمت هذه الخصائص بنوع الاستثمار فى هذه المقاهى سواء قطاع خاص او حكومى وكذلك عدد العمال بها ونوعية الخدمات التى تقدمها هذه المقاهى كما يتضح من جدولى (ع ) و ( )
1 - خصائص المقاهي : تم الاعتماد فى دراسة هذه الخصائص على اخذ عينة عشوائية من هذه المقاهى وتوزيع استمارات استبيان عليها وكانت من أهم نتائجها كما يلى : أ-الخصائص الجغرافية والخدمية للمقاهي :

جدول ( ) ) الخصائص الجغرافية والخدمية للمقاهي

\begin{tabular}{|c|c|c|c|c|c|c|c|c|c|}
\hline نوع & جنسية & الموظفين & نوع الخدمات المقدمة & المهولة & الاخرى & تاريخ & موقع المقهى & مكان وجوده & اسم المقهى \\
\hline انثى & 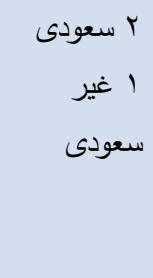 & $r$ & - - - - - مأكولات ومشروبئل الترفيه - الأسعار مناسبة - & تمويل & لا يوجد & $1 \leqslant r V$ & الحي الراقي & تجارى & 雪。 \\
\hline انثى & T ب سعودى & $\wedge$ & 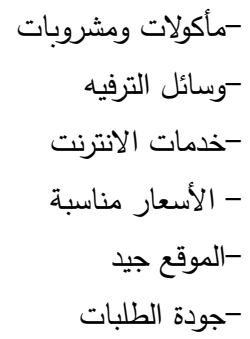 & تمويل & لا يوجد & - & الضيافة & موقع مستقل & $\begin{array}{l}1 \\
3 \\
3 \\
3 \\
37 \\
: 3\end{array}$ \\
\hline انثى & سعودى & r & مأكولات ومشروبات & تمويل & لا يوجد & - & الرصراص & موقع مستقل & $\begin{array}{l}\frac{7}{3} \\
\text { y. } \\
\text { के }\end{array}$ \\
\hline ذكر & غير سعودى & r & 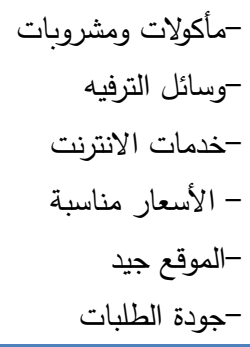 & القطاع من & (الواحه & $1 \leqslant r \leqslant$ & الدرب ل & تجارى داخل مول & 来; \\
\hline ذكر & T ب سعودى & $\wedge$ & 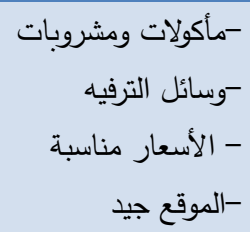 & تخويل & الحسام) نعم (حى & - & المعارض & تجارى & $\frac{3}{\frac{3}{3}}$ \\
\hline
\end{tabular}




\begin{tabular}{|c|c|c|c|c|c|c|c|c|c|}
\hline & & & -جودة الطلبات & & & & & & \\
\hline ذكر & غير سعودى & r & - مأكولات ومشروبات & شخويل & y & $1 \leqslant r V$ & الحرابى & تجارى مول & $\begin{array}{l}3.3 \\
3 \\
3\end{array}$ \\
\hline انثى & غعردى سعودى & - & - -مأكولات ومشروبات - -لموقع جبدات & شخويل & المطم (حى) & - & الحضارى & موقع مستقل & $\begin{array}{l}\frac{3}{3} \\
3 \\
\cdot 3\end{array}$ \\
\hline انثى & غعير سعودى & $1=p$ & 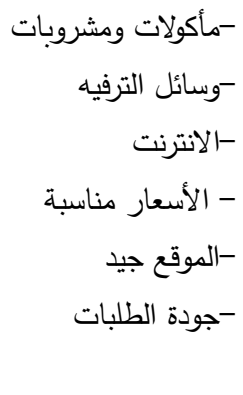 & ش & ع ع لا يوجد & - & & مـ مول ماخل موقع & الإجمالي \\
\hline
\end{tabular}

المصدر: من عمل الباحثة اعتمادا على تحليل استمارات الاستبيان.

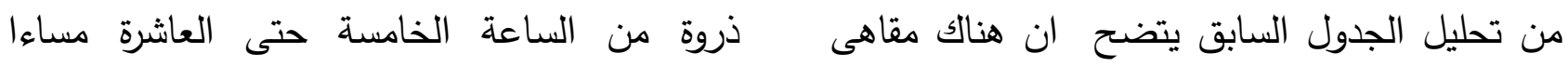

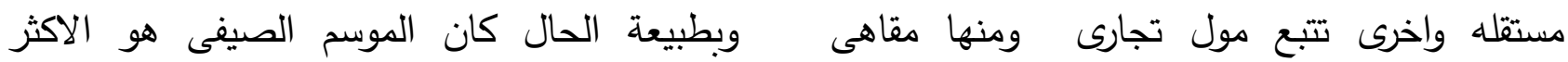

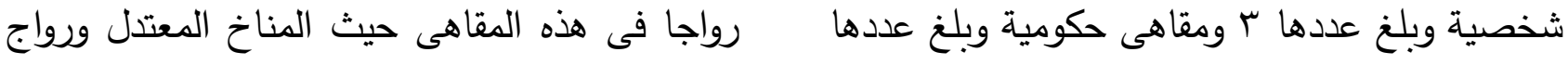

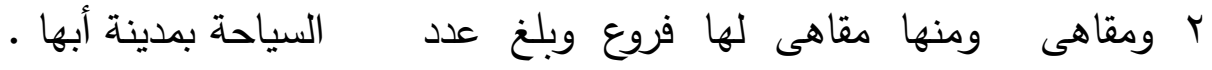

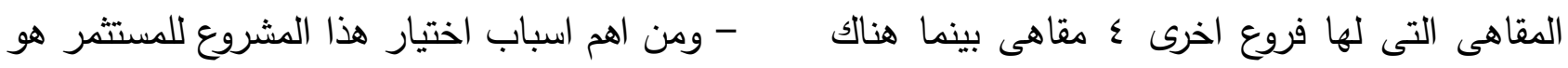

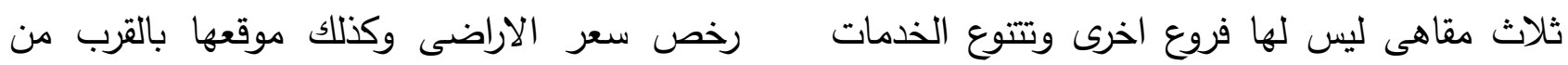

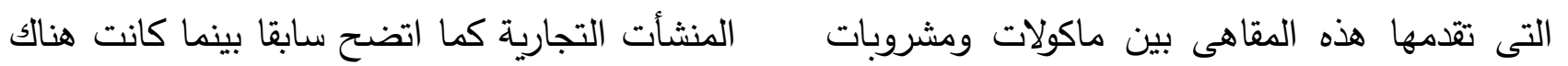

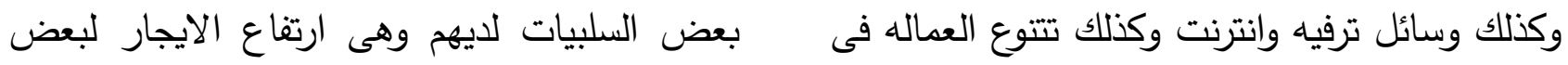

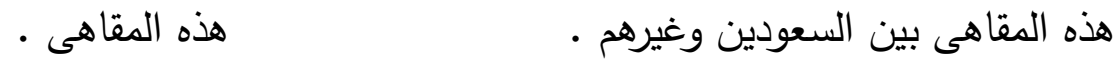
ب-الخصائص المالية والزمانية والمشكلات التي - من مقترحات رواد المقاهى زيادة الايدى العامله

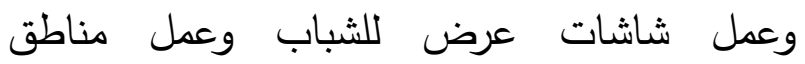
تواجهها الدقاهى : استضافة للاطفال

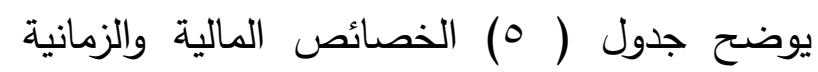

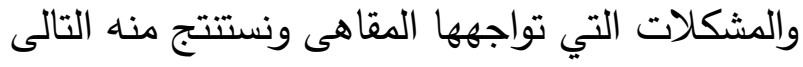

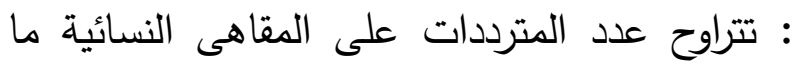

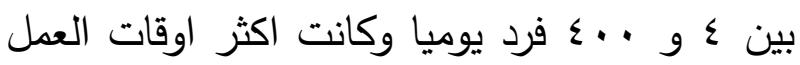


جدول ( ) الخصائص المالية والزمانية والمشكلات التي تواجهها المقاهى

\begin{tabular}{|c|c|c|c|c|c|c|c|c|c|}
\hline مقترحات & التي تواجهلات & لداجى ايفائه & سبب اختيار موقع & المخل اليوميط & أكثر المواسم & أكثر & أكثر & عدد & اسم المقهى \\
\hline & المرتفع & يفي بالحاجة & رغهولة الوصول & ه-1. & الصيف & الجميس، البعة & الصصباح- & $r \cdot-\varepsilon$ & 雪 \\
\hline & الاليجار & يفي بالحاجة & رغهولة الوصول & الاف من & الصيف & الاربعاء & المغرب & 0. & $\begin{array}{l}-1 \\
3 \\
3 \\
3 \\
.7\end{array}$ \\
\hline \multirow[t]{4}{*}{ الأليجار } & المرتفع & لا لايفي & رغور مسجد المستثر & الاقل من & الصيف & الخميس الأربعاء & الصباح & $\varepsilon-r$ & $\begin{array}{l}\frac{7}{7^{2}} \\
\text { के }\end{array}$ \\
\hline & الاليجار & يفي بالحاجة & كثرة المترددين المستثر & الافل من & الصيف & الجبت الجعة & $r^{\wedge-V}$ & $r \cdot-1$. & 寻 \\
\hline & ضيق & يفي بالحاجة & رنهولة الوصول & الاف من & الصيف & الجمعة الجمس & العشاء - المغرب- & $r$. & $\frac{\sqrt[3]{9}}{\frac{3}{3}}$ \\
\hline & الايجار & يفي بالحاجة & رغأر رغبة المستثر & ه-1. & الصيف & الجمعة & من O- V م & $1 \ldots$ & $\begin{array}{l}3.3 \\
3 \\
3\end{array}$ \\
\hline شراشات & الالمنافة & يفى بالحاجة & رغولة الوصتئر & الاف ريال & الصيف & الجميس العمعلات & من & $\varepsilon \ldots-\uparrow \ldots$ & $\begin{array}{l}3 \\
3 \\
3\end{array}$ \\
\hline
\end{tabular}


المصدر : من عمل الباحثة اعتمادا على تحليل استمارات الاستبيان.

خميس مشيط والمكونة من ع ب وكانت النتائج كما

$$
\text { : }
$$

ب - خصائص المترددات على المقاهى النسائية.

\section{r}

يوضح جدول ( ب آ) جنسية المترددات على المقاهى

تم الاعتماد فى دراسة هذه الخصائص على تحليل حيث كان السواد الاعظم من السعوديات بنسبة البيانات التي تم تجمعيها من الاستمارة رقم (r) تصل الى اكثر من 90. \% م من المترددات على هن

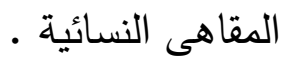

\begin{tabular}{|c|c|c|c|}
\hline الإجمالي & غير سعودية & سعودية & الجنسية \\
\hline$I V \varepsilon$ & $\wedge$ & 177 & التكرار \\
\hline $1 \ldots$ & $\% \varepsilon, 7$ & $\% 90, \varepsilon$ & $\%$ \\
\hline
\end{tabular}

جدول (†) جنسيات المترددات على المقاهى النسائية بمدينة خميس مشيط لهيط

المصدر: من عمل الباحثة اعتمادا على تحليل استمارات الاستبيان.

اكثر من V^ \% من المترددات يأتون من داخل

r- موقع السكن

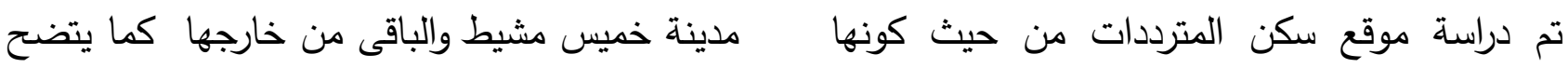

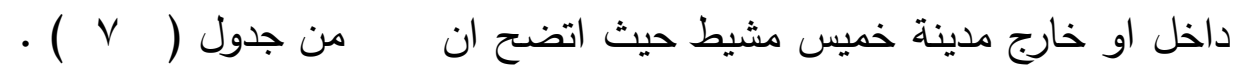

\begin{tabular}{|c|c|c|c|}
\hline الإجمالي & خارج مدينة خميس & داخل مدينة خميس & الموقع \\
\hline $\mid V \varepsilon$ & r & 144 & التكرار \\
\hline $1 \ldots$ & $r^{\prime}, \Lambda$ & $V \Lambda, r$ & $\%$ \\
\hline
\end{tabular}
جدول (V): موقع سكن المترددات على المقاهى النسائية بمدينة خميس مشيط

المصدر: من عمل الباحثة اعتمادا على تحليل استمارات الاستبيان.

وبالتالى يعطى العلاقة ما بين موقع النشاط (الخدمة)

ـ - سهولة الوصول للمقاهى النسائية فى مدينة

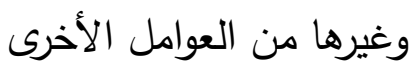

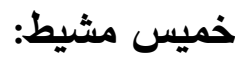

(Al Sahili, K and Aboul-.1999, p.86) يقصد بسهولة الوصول هو قدرة الأشخاص والبضائع Ela, على التحرك والتتقل من مكان لآخر بسهولة ويسر التهول أو ما بين نقاط متعددة ويجب الإشارة بأن وسائل 


$$
\text { حنان عبد الهادي سعيد القاضي القحطاني }
$$

التقنية الحديثة قد أثرت بصورة فعالة على توزيع يدفعها القائم بها أو الوقت المستغرق للقيام بها

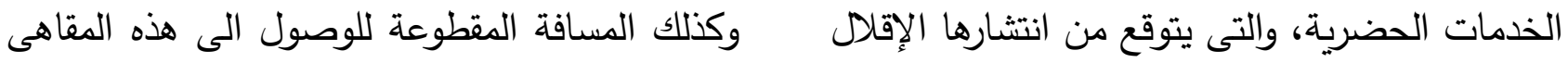
كما يتضح من جدول ( 1 ) وجدول ( 9 ( ) . من عدد الرحلات بين نقطتين

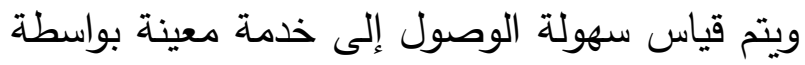
تكلفة الرحلة ، أى أن ما تكلفه هذه الرحلة من مبالغ لودئ

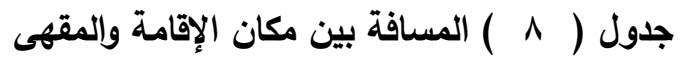

\begin{tabular}{|c|c|c|c|}
\hline الترتيب حسب بعد & الانحراف المعياري (ع) & متوسط المسافة بين مكان & اسم المقهى \\
\hline r & rr,q) & $r r, .$. & تيفاني \\
\hline v & $\vee, 91$ & $1 \cdot, \pi r$ & جلسة هادئة \\
\hline$r$ & $\Lambda, \vee$. & $r, 0$. & دايت كوفي \\
\hline 7 & $\lambda, Y_{1}$ & $17, \mathrm{ro}$ & سنيون \\
\hline 1 & $\mu_{\uparrow, \ldots}, \ldots$ & $\Delta \wedge, \ldots$ & سوفليه الواحة \\
\hline 。 & $r q, \uparrow \wedge$ & $1 \wedge, \ldots$ & سيحة بال \\
\hline$\varepsilon$ & Y , १ & $r \cdot, q \varepsilon$ & ماما روتى \\
\hline - & rr,q) & $r r, 1$. & الاجمالى \\
\hline
\end{tabular}

المصدر: من عمل الباحثة اعتمادا على تحليل استمارات الاستبيان.

ه- مدة الوصول بين مكان الإقامة وإلمقهى : يستغرق الوصول للمقاهى بأنواعها المختلفة فترة

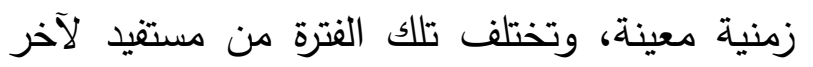

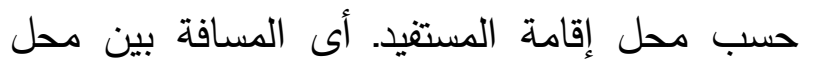

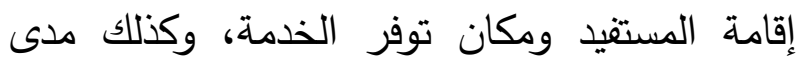
كثافة انتشار الخدمة، بالإضافة إلى نوع الوسيلة

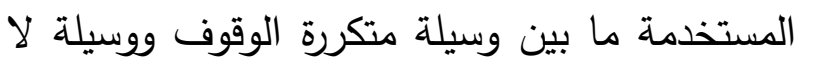
تتوقف إلا عند المقصد، بالإضافة إلى سهولة الحركة وهذا مرتبط بشبكة الشوارع واتساعها فى المدينة،
وبالرغم من التقدم الذي طرأ على تقنية المواصلات

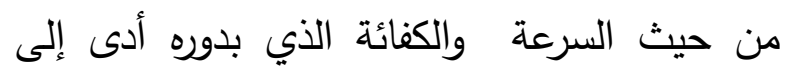
اختصار الزمن وتقليل المسافة ( أبو صبحة 2002 , ر ) ومن تحليل جدول ( ) ) يتضح ان النفوذ الاقليمى للمقاهى النسائية بمدينة خميس مشيط يمتد

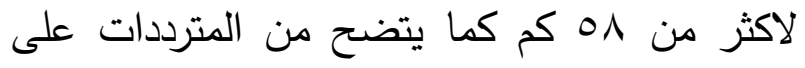

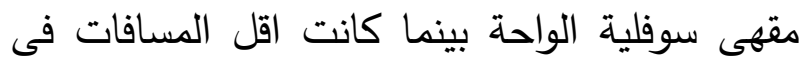
مقهى جلسة هادئة لمسافة تصل لى نحو · ل اكم ، بينما كان متوسط المسافة بين الاقامة والمقهى نحو

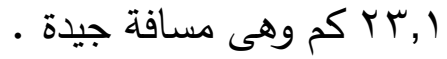


والجدول التالى يوضح المسافة الزمنية للوصول إلى المقاهى النسائية بمدينة خميس مشيط . جدول (9 ) مدة الوصول بين مكان الإقامة والمقهى الفي

\begin{tabular}{|c|c|c|}
\hline الانحراف المعياري (ع) & متوسط مدة الوصول (دقيقة) & اسم المقهى \\
\hline 11,74 & $r \cdot, 7)$ & تيفاني \\
\hline $11, \leqslant 7$ & $r \cdot, l \varepsilon$ & جلسة هادئة \\
\hline $1 T, r$ A & $19, v \varepsilon$ & دايت كوفي \\
\hline 9,00 & $\mid \Lambda, \uparrow \Lambda$ & سنيون \\
\hline $1 \cdot, \wedge 9$ & $r \varepsilon, \cdot$. & سوفليه الواحة \\
\hline $1 \cdot, 71$ & $r_{0}, \sum 0$ & سيحة بال \\
\hline Ir,YO & $1 \Lambda, \Sigma Y$ & ماما روتى \\
\hline $11, \varepsilon V$ & $r, \mid v$ & الاجمالى \\
\hline
\end{tabular}

المصدر: من عمل الباحثة اعتمادا على تحليل استمارات الاستبيان.

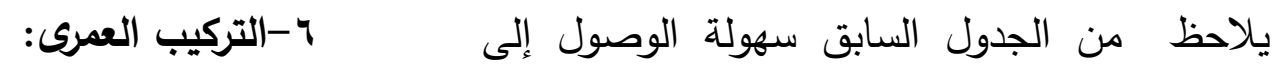
المقاهى النسائية بمدينة خميس مشيط ، حيث بيتلب التعامل مع المقاهى النسائية فى مدينة

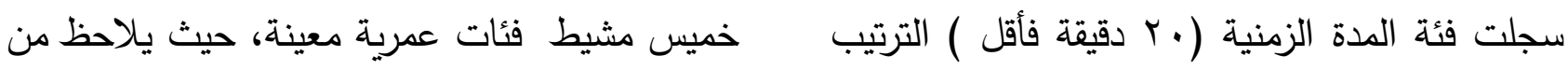

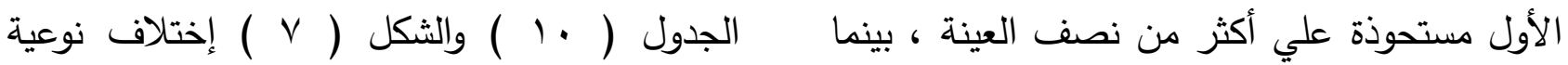

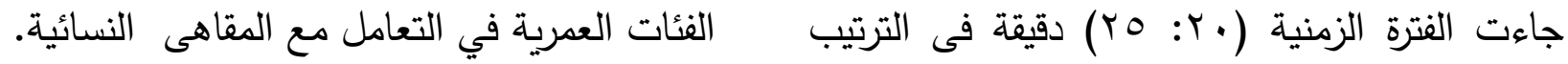

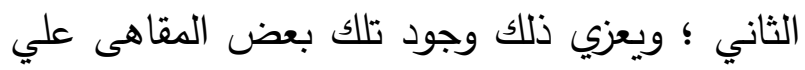

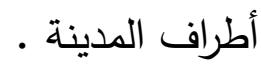

جدول ( ا ) التركيب العمرى للمترددات على المقاهى النسائية بمدينة خميس مشيط بالعينة

\begin{tabular}{|c|c|c|}
\hline النسبة المئوية & التكرار & المرحلة العمرية \\
\hline$\% \backslash \vee, r$ & r. & اقل من · r سنة \\
\hline$\% \varepsilon \cdot, r$ & $v \cdot$ & من ·ro-r \\
\hline$\% \curlyvee \wedge, \vee$ & 0. & من צr- . ؛ \\
\hline$\% \backslash r, \wedge$ & $r \varepsilon$ & من إ -فاكثر \\
\hline
\end{tabular}

المصدر: من عمل الباحثة اعتمادا على تحليل استمارات الاستبيان. 
شكل ( V ) المراحل العمرية لمترددات على المقاهى النسائية بمدينة خميس

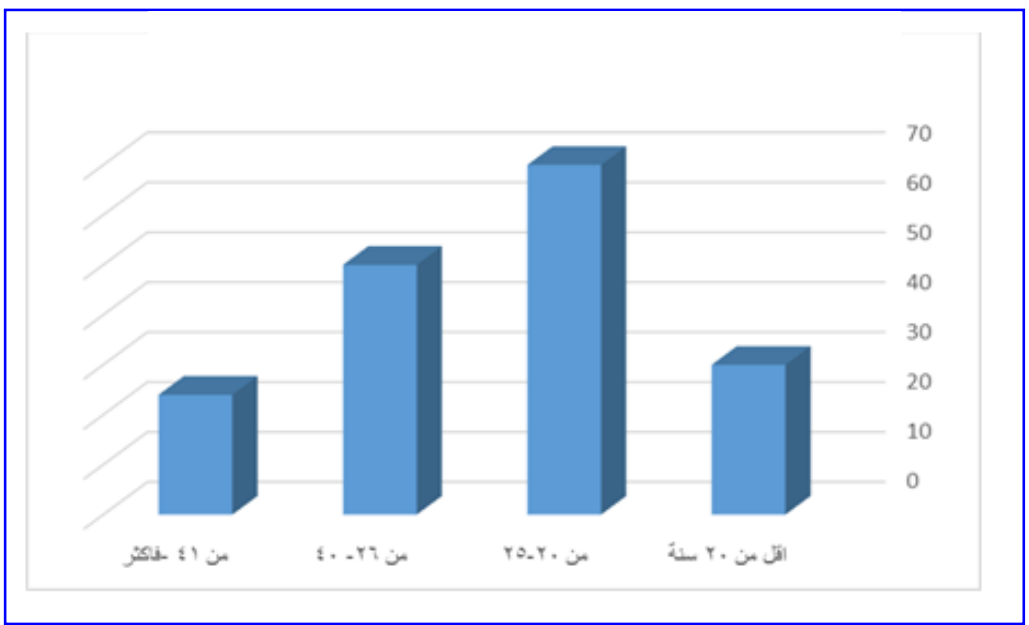

المصدر : من عمل الباحثة اعتمادا على بيانات

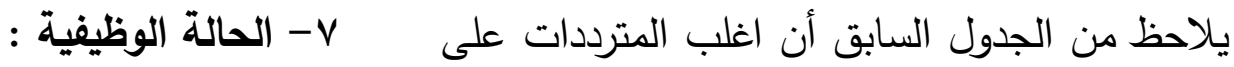
المقاهي من المرحلة العمرية (من •r-ro ) حيث للوظيفة دور مهم في تحديد نوعية العميل أو

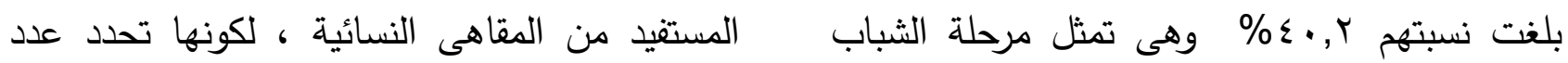
المبكرة ، في حين كانت اقل نسبة من ذوات الفئة مرات التردد على هذه المقاهى وإمكانية التعامل معها، وكذلك البعد الاقتصادى فى التعامل مع هذه

العمريـة (من اء فاكثر)

المقاهى وهذا ما يوضحة الجدول التالي:

جدول (11 ) الحالة الوظيفية للممترددات على المقاهى النسائية بمدينة خميس مشيط بالعينة

\begin{tabular}{|c|c|c|}
\hline النسبة المئوية & التكرار & الحالة الوظيفية \\
\hline$\% \leqslant q, \varepsilon$ & $\wedge T$ & طالبة \\
\hline \%rr & $\varepsilon$. & موظفة \\
\hline$\%$ \%०,r & $\varepsilon \varepsilon$ & ربة منزل \\
\hline$\% r, r$ & $\varepsilon$ & أخرى \\
\hline
\end{tabular}

المصدر : من عمل الباحثة اعتمادا على تحليل استمارات الاستبيان.

يلاحظ من الجدول السابق أن اغلب مرتادات وأتت في المرتبة الثانية ربات المنزل يليها

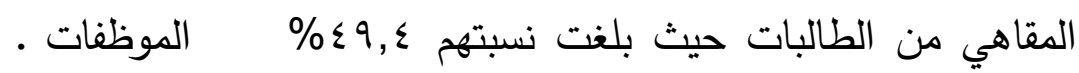


الأشخاص ممن ليس لديه القدرة على القراءة والكتابة

^- الحالة التعليمية : تحدد الحالة التعليمية قدرة المترددات على هذه إلي متاعب وصعوبات ، والجدول التالي يوضح التئح

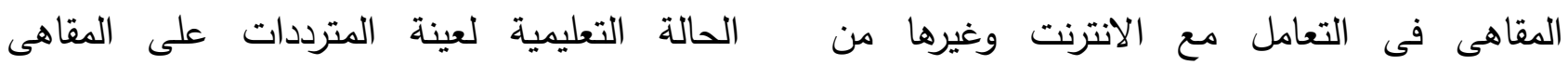

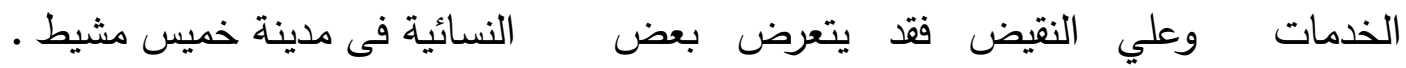
جدول ( r r ) الحالة التعليمية للمترددات على المقاهى النسائية فى مدينة خميس مشيط بالعينة

\begin{tabular}{|c|c|c|}
\hline النسبة المئوية & التكرار & الحالة التعليمية \\
\hline$\% 1,1$ & r & امى \\
\hline$\% 1, \vee$ & $r$ & ابتدائي \\
\hline$\% ヶ, \varepsilon$ & 7 & متوسط \\
\hline$\%$ \%r & $\varepsilon$. & ثانوي \\
\hline$\% ч \cdot, q$ & 1.7 & جامعي \\
\hline$\% 9, \wedge$ & IV & فوق الجامعي \\
\hline$\% 1 \ldots$ & $\mid V \varepsilon$ & الاجمالى \\
\hline
\end{tabular}

المصدر: من عمل الباحثة اعتمادا على تحليل استمارات الاستبيان.

شكل ( 9 ) الحاله التعليمية لمترددات على المقاهى النسائية بمدينة خميس مشيط بالعينة

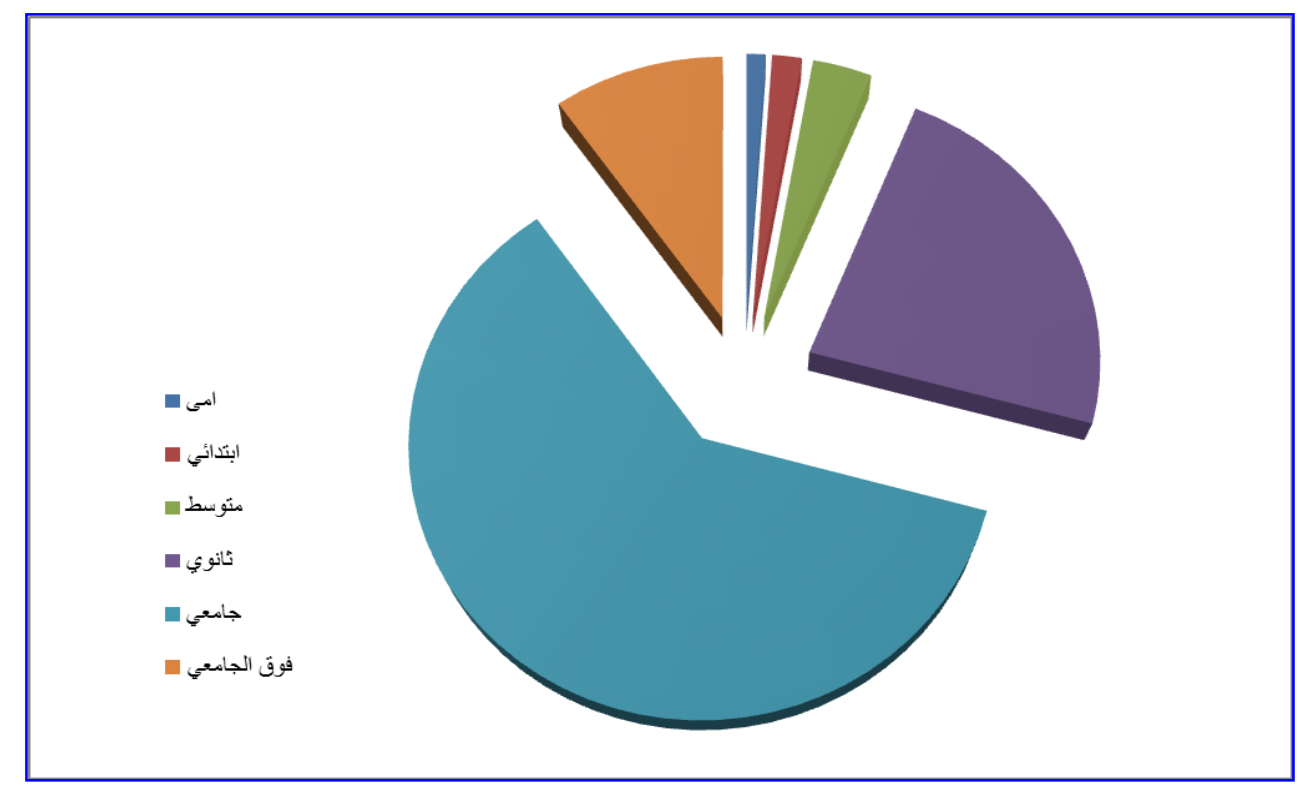

المصدر : من عمل الباحثة اعتمادا على بيانات جدول ( r ) 


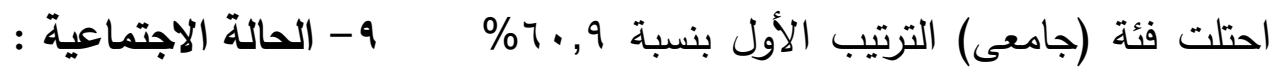
من جملة العينة؛ ويرجع ذلك إلي خبرتهم وإدراكهم تعتبر الحالة الاجتماعية مؤشراً أساسياً عند دراسة

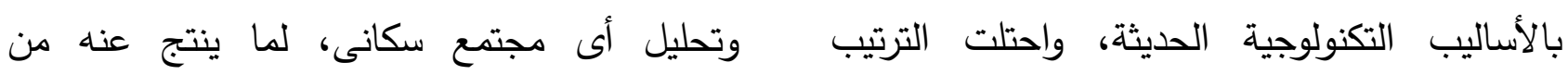

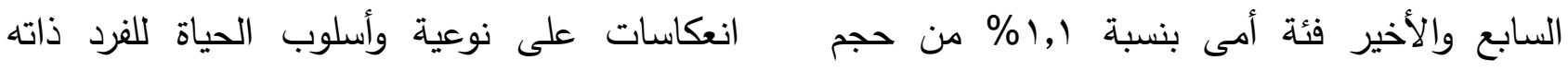

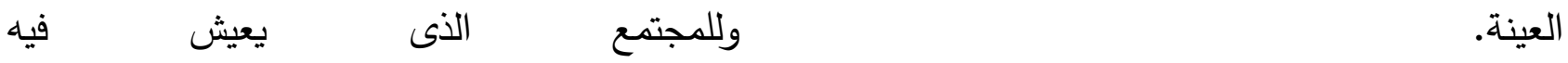

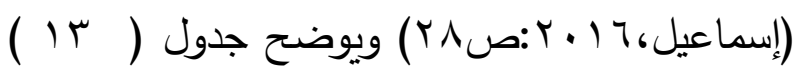

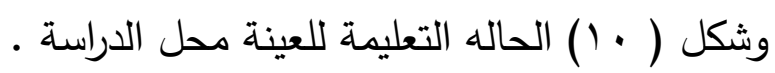

جدول ( T1 ) الحالة الاجتماعية للمترددات على المقاهى النسائية فى مدينة خميس مشيط بالعينة

\begin{tabular}{|c|c|c|}
\hline النسبة المئوية & التكرار & الحالة الاجتماعية \\
\hline$\% \circ r, q$ & 94 & عزباء \\
\hline$\% 0, r$ & 9 & مطلقة \\
\hline$\% r \vee, q$ & 77 & متزوجة \\
\hline$\% \varepsilon$ & v & ارملة \\
\hline$\% 1 \ldots$ & $I V \varepsilon$ & الاجمالى \\
\hline
\end{tabular}

المصدر : من عمل الباحثة اعتمادا على تحليل استمارات الاستبيان.

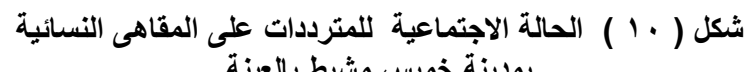
بمدينة خميس مشيط بالعينة

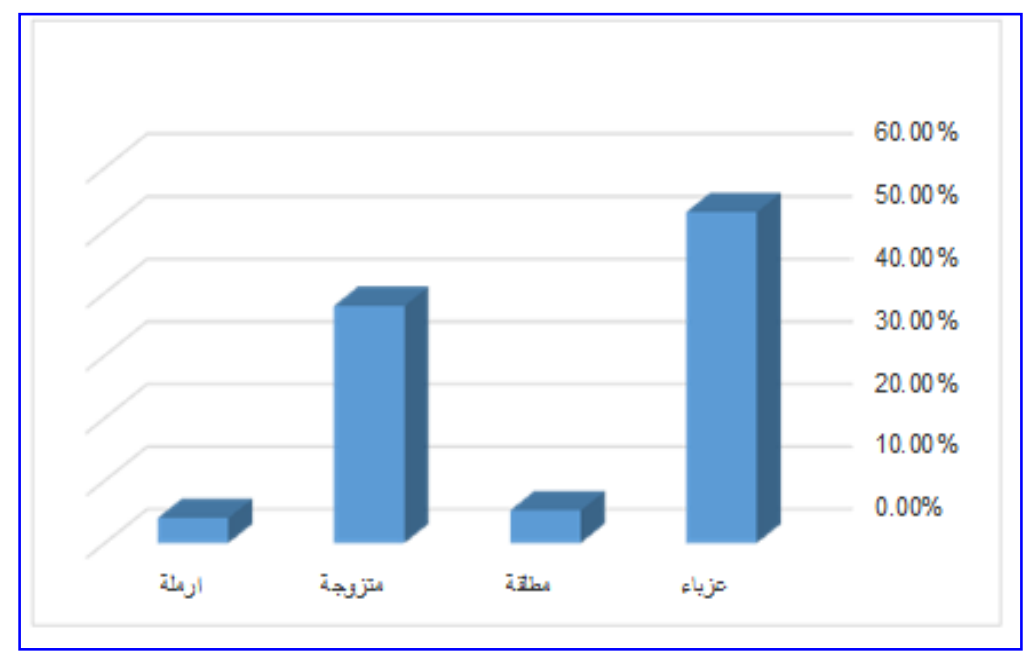

المصدر : من عمل الباحثة اعتمادا على بيانات 
يلاحظ من الجدول السابق أن اغلب المترددات على السكن :

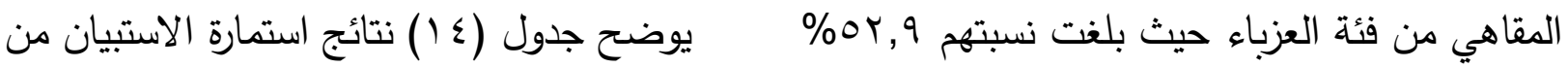

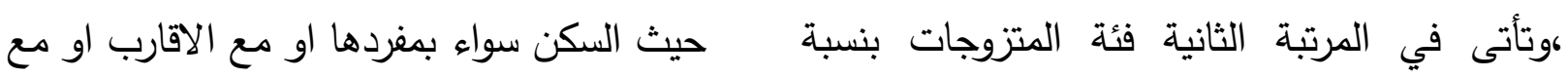

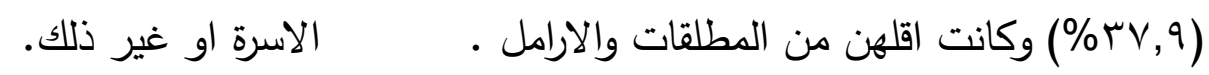

جدول (ع 1) حاله السكن للمترددات على المقاهى النسائية فى مدينة خميس مثيط بالعينة

\begin{tabular}{|c|c|c|}
\hline النسبة المئوية & التكرار & السكن \\
\hline$\% r, \varepsilon$ & 7 & بمفردها \\
\hline$\% 1,1$ & r & مع الأقارب \\
\hline$\% q r, V$ & $17 \pi$ & مع الاسرة \\
\hline$\%$ १, ২ & $r$ & مع الاصدقاء \\
\hline$\% 1 \ldots$ & $\mid V \varepsilon$ & الاجمالى \\
\hline
\end{tabular}

المصدر: من عمل الباحثة اعتمادا على تحليل استمارات الاستبيان.

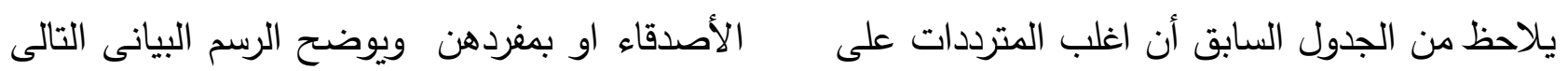

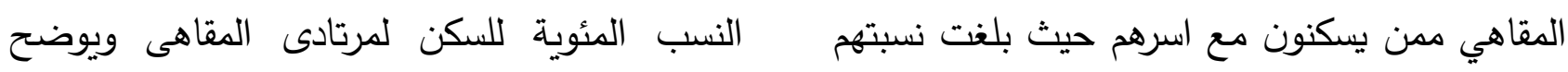

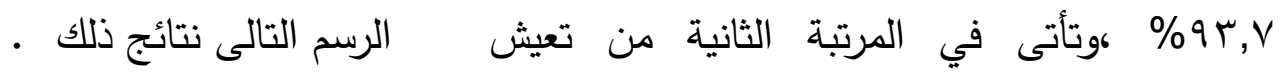

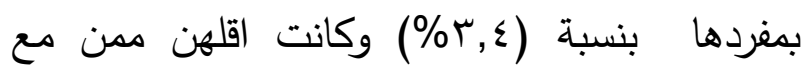
شكل ( 11 ) حاله السكن لمترددات على المقاهى النسائية بمدينة خميس مشيط بالعينة

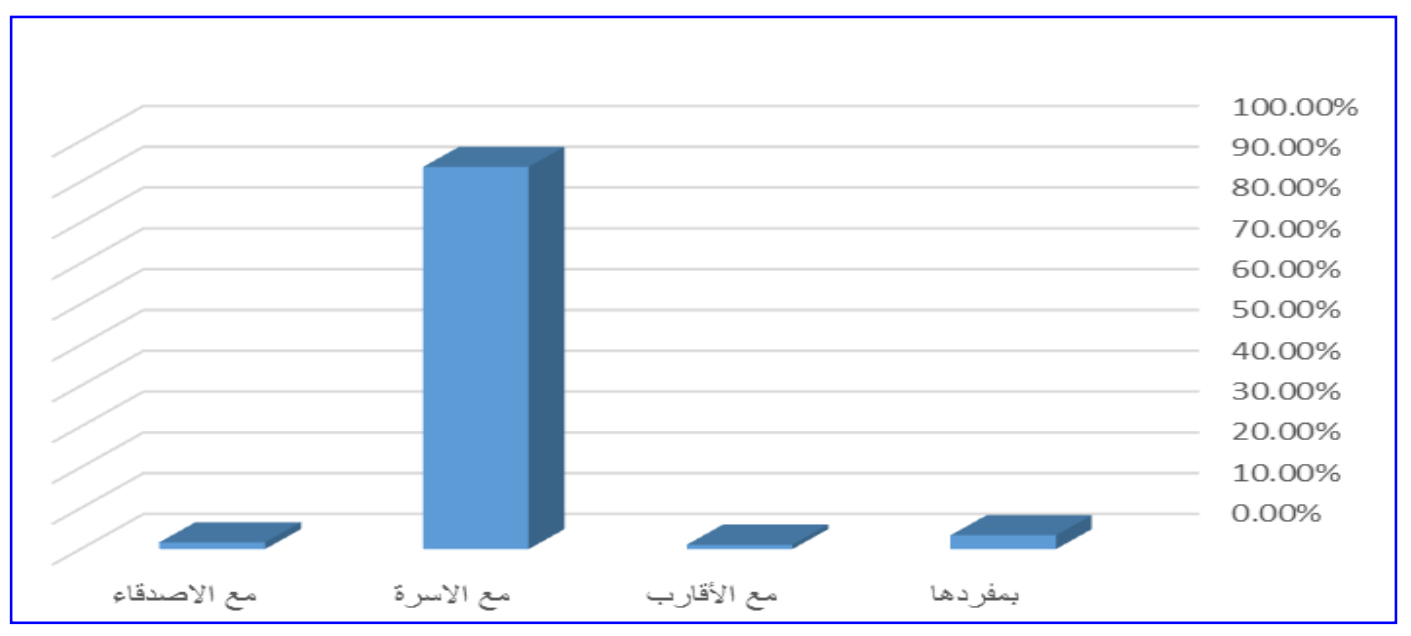

المصدر : من عمل الباحثة اعنمادا على، بيانات جدول ( ـ ا ) 
تم دراسة عدد افراد اسر المترددات بما يؤثر ذلك على المستوى الاقتصادى للاسرة وكانت النتائج كما يتضح من جدول (10) - (10)

جدول (0 1 ):عدد افراد اسر المترددات على المقاهى النسائية فى مدينة خميس مشيط بالعينة

\begin{tabular}{|c|c|c|}
\hline النسبة المئوية & التكرار & عدد افراد الاسرة \\
\hline$\% r, r$ & rv & اقل من ؛ اشخاص \\
\hline$\% \circ \leqslant$ & $9 \leqslant$ & من \& \& اشخاص \\
\hline$\% r \varepsilon, r$ & $\varepsilon r$ & اكثر من V اشخاص \\
\hline$\% 1 \ldots$ & $1 V \varepsilon$ & الاجمالى \\
\hline
\end{tabular}

المصدر : من عمل الباحثة اعتمادا على تحليل استمارات الاستبيان.

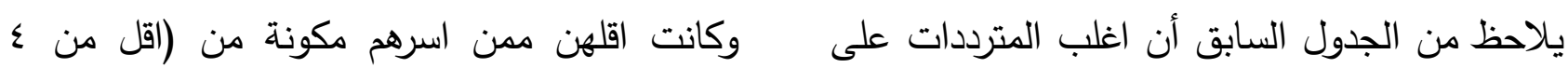

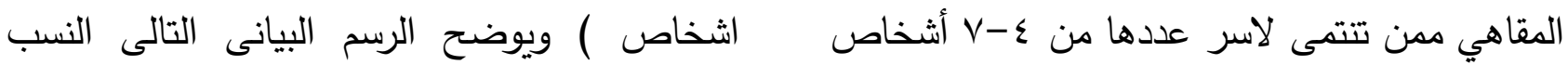
حيث بلغت نسبتهم ع٪\%، وتأتى في المرتبة الثانية المئوية لعدد افراد الاسرة لمرتادى المقاهى ويوضح

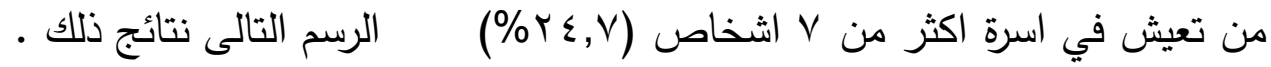

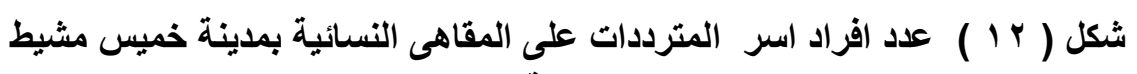
بالعينة

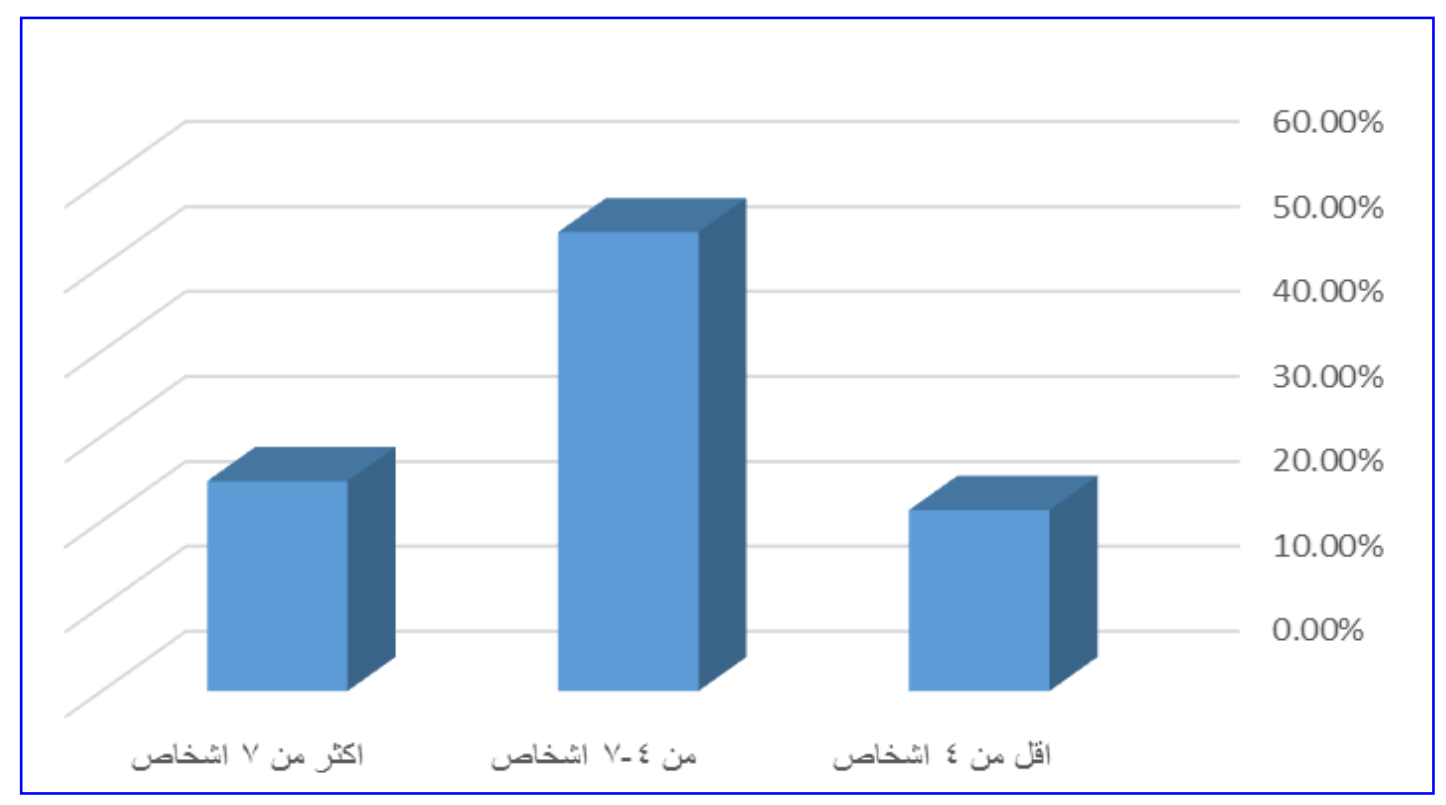

المصدر : من عمل الباحثة اعتمادا على بيانات جدول (10 ) 
r ا - متوسط الاخل الثهرى :

تباينت مستويات الدخل بين فئات مستخدمي المقاهى النسائية بمدينة خميس مشيط ، حيث تعتبر من الأسس المهمة التى توضح مستويات المعيشة ودليل علي مدي احتياج السكان للمقاهى ، وتبين من دراسة الجدول :

جدول (17 ) متوسط دخل للمترددات على المقاهى النسائية فى مدينة خميس مشيط بالعينة

\begin{tabular}{|c|c|c|}
\hline النسبة المئوية & الت التكرار & متوسط الاخل \\
\hline$\% \leq 7,7$ & 1) & اقل من ... . ر ريال \\
\hline$\%$ \%r,, & $\varepsilon$ & من .......... \\
\hline$\% \curlyvee q, r$ & or & اكثر من ... جربيال \\
\hline$\% 1 \ldots$ & $\mid V \varepsilon$ & 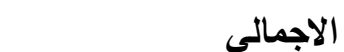 \\
\hline
\end{tabular}

المصدر : من عمل الباحثة اعتمادا على تحليل استمارات الاستبيان.

شكل ( r 1 ) عدد افزاد للمترددات على المقاهى النسائية بمدينة خميس مشيط بالعينة 
يلاحظ من الجدول السابق أن اغلب مرتادات ب ا - الخصائص الايموغرافية لمرتادى المقاهى

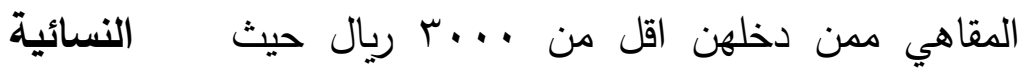
بلغت نسبتهم 7,7؟\% ، ، وتأتى في المرتبة الثانية من التحليل السابق يمكن تلخيص اهم الخصائص

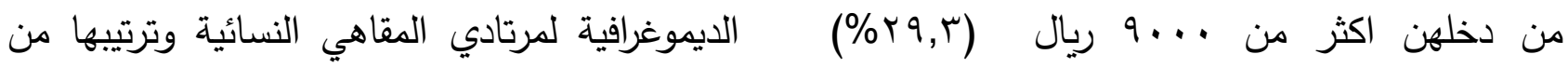

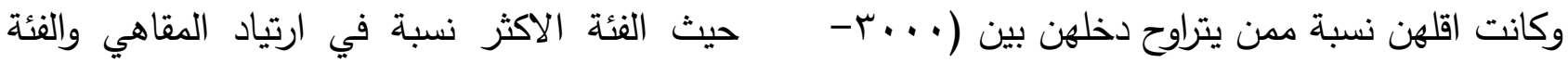

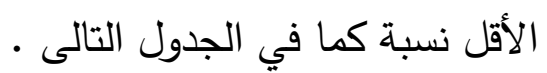

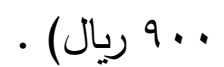

جدول ( IV ) الخصائص الايموغرافية لمرتادى المقاهى النسائية بالعينة

\begin{tabular}{|c|c|c|c|}
\hline اقل فئة ترتاد المقهى & أكثر فئة ترتاد المقهى & الخاصية الديموغرافية & r \\
\hline غير سعودية (ך,§؟\%) & سعودية (乏, 90\%) & جنسية المترددين & 1 \\
\hline خارج مدينة خميس & داخل مدينة خميس (r\%ノ, (\%) & موقع السكن & \\
\hline 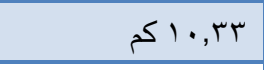 & S01 & المسافة بين مكان الإقامة والمقهى & $r$ \\
\hline 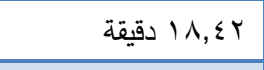 & 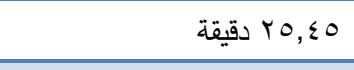 & مدة الوصول بين مكان الإقامة والمقهى & $\varepsilon$ \\
\hline من إ عام فاكثر & من ·r- ro عام & اعمار مرتادي المقهى & ○ \\
\hline موظفة (سYY\%) & طالبة (£, ؟ \%\%) & الحالة الوظيفية & 7 \\
\hline امية (1,1\%) & مؤهل جامعي (9, • 7\%\%) & الحالة التعليمية & $v$ \\
\hline ارملة (£٪\%) & عزباء (9,9\% & الحالة الاجتماعية & $\wedge$ \\
\hline مع الأقارب (1,1\%) & مع الاسرة (†qץ\%) & السكن & 9 \\
\hline 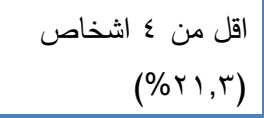 & 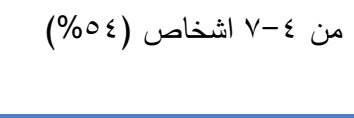 & عدد افراد الاسرة & 1. \\
\hline اكثر من ... 9 ريال & اقل من ... ب ريال & متوسط الاخل الثهرى & 11 \\
\hline
\end{tabular}

المصدر: من عمل الباحثة اعتمادا على تحليل استمارات الاستبيان.

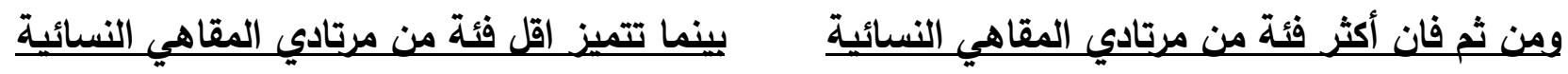
بالاتي: تتميز بالخصائص الاتية:

غير سعودية - من خارج مدينة خميس - اعمارهن

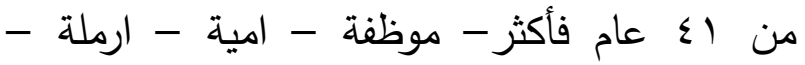

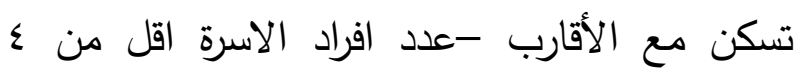
اشخاص - الدخل أكثر من . .. . 9 ريال. ؛ 1 -الخصائص البيئية والزمانية والمكانية والنفسية المميزة لمرتادي المقاهي :
سعودية - تسكن داخل خميس مشيط - اعمارهن

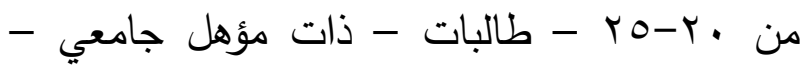

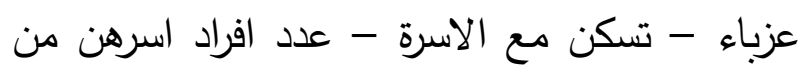
ع- اشخاص - متوسط دخلهن الثهرى اقل من

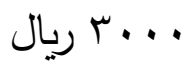


تتناول هذه الخصائص دراسة عدد مرات زيارة أ- عدد مرات زيارة المقهى: المقاهى وموعد الزيارة ومعدل الصرف واسباب الزيارة يوضح جدول ( 1 1) استمارات الاستبيان فى تكرارية والافضلية بين هذه المقاهى وكانت النتائج كما يلى : عدد مرات زياة المقاهى النسائية . جدول (1 1 ) عدد مرات زبارة المقهى للمترددات على المقاهى النسائية بمدينة خميس مشيط بالعينة

\begin{tabular}{|c|c|c|}
\hline النسبة المئوية & التكرار & عدد مرات الزيارة \\
\hline$\% \curlyvee, r$ & $\varepsilon$ & يوميا \\
\hline$\% \varepsilon, 7$ & $\wedge$ & خلال الأسبوع \\
\hline$\% \varepsilon r$ & vr & نهاية الأسبوع \\
\hline$\% r \leqslant, 0$ & 7. & مرة في الثهر \\
\hline$\% 17, \vee$ & rq & مرة في السنة \\
\hline$\% 1 \ldots$ & $1 v \varepsilon$ & الإجمالي \\
\hline
\end{tabular}

يلاحظ من النتائج المعروضة في الجدول السابق ان غالبية المرتادات للمقاهى يقمن بزيارة المقاهى في نهاية الأسبوع او مرة واحدة في الثهر ونادرا ما يقدن بالزيارة يوميا شكل ( ؛ 1 ) عدد مرات زيارة المقاهى للمترددات على المقاهى النسائية بمدينة خميس مشيط بالعينة

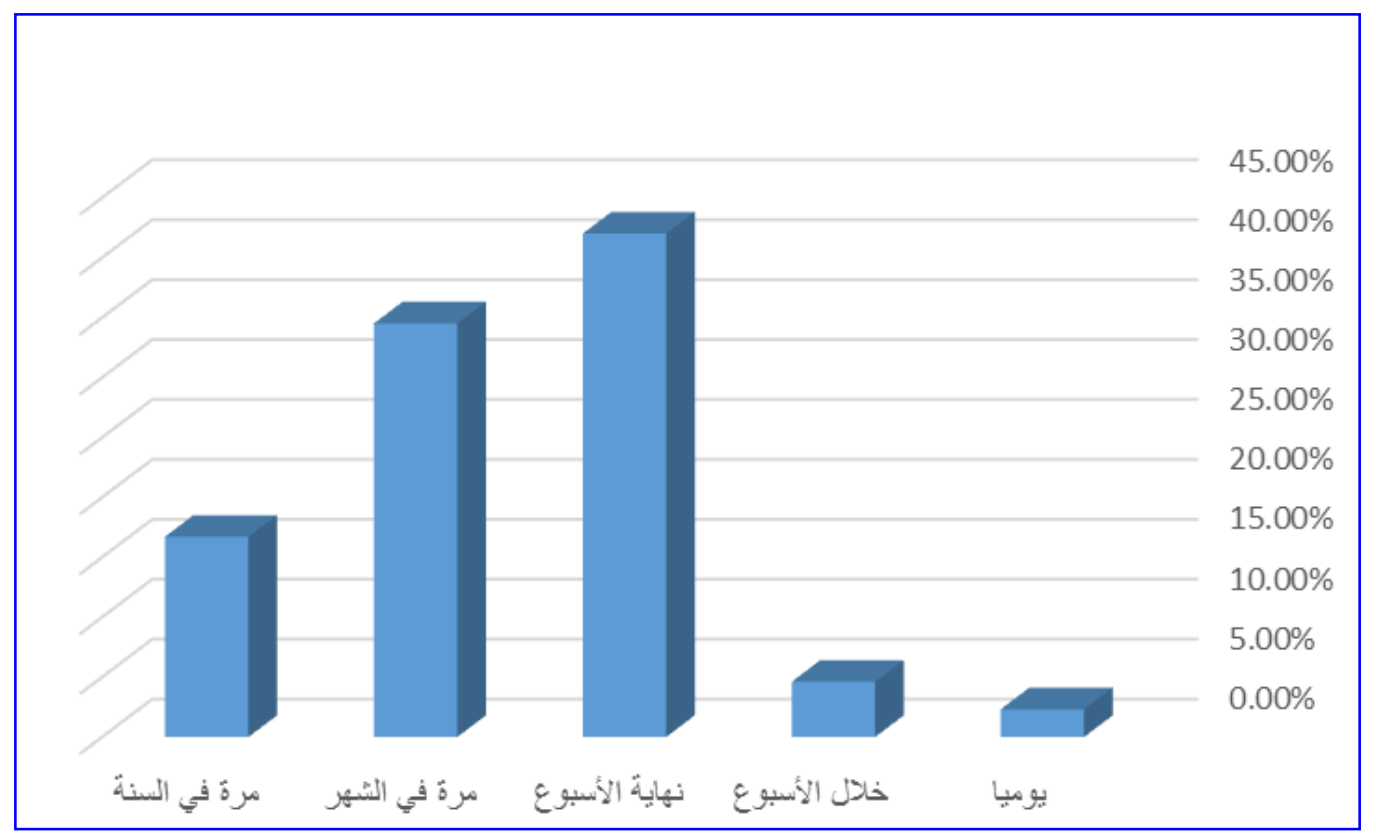

المصدر : من عمل الباحثة اعتمادا على بيانات جدول ( 11 ) 
ب -مدى ملائمة موقع المقهى:

يوضح الجدول التالى مدى ملائمة موقع المقاهى للمترددات فى مدينة خميس مشيط موليط جدول (9 1 ) مدى ملائمة موقع المقهى بالنسبة للمترددات على المقاهى النسائية بمدينة خميس مشيط بائية بالعينة

\begin{tabular}{|c|c|c|}
\hline النسبة المئوية & هى التكرار & مدى ملائمة موقع المقهى \\
\hline$\% \wedge \vee, q$ & 104 & ملائم \\
\hline$\% \backslash r, 1$ & ru & غير ملائم \\
\hline$\% 1 \ldots$ & $I V \varepsilon$ & الإجمالي \\
\hline
\end{tabular}

المصدر: من عمل الباحثة اعتمادا على تحليل استمارات الاستبيان.

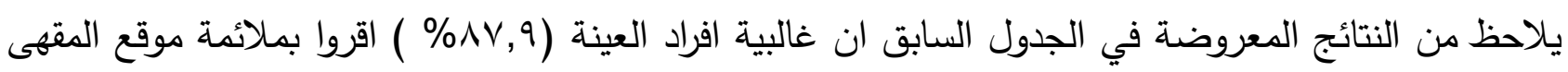

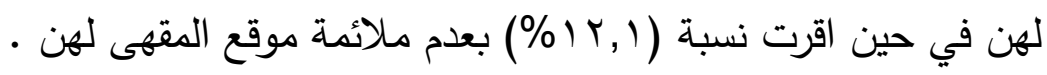
ج-موعد زيارة المقهى:

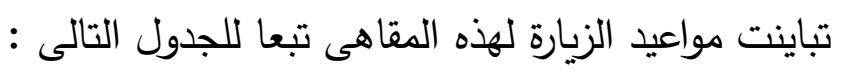
جدول (·r ) مواعيد زيارة المقاهى للمترددات على المقاهى النسائية بمدينة خميس مشيط بالعينة

\begin{tabular}{|c|c|c|}
\hline النسبة المئوية & التكرار & موعد زيارة المقهى \\
\hline$\% ५, \varepsilon$ & 7 & 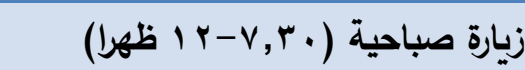 \\
\hline$\%$ \%r & $\varepsilon$. & 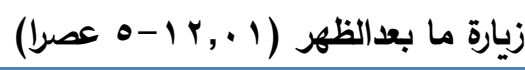 \\
\hline$\% \vee r, r$ & IrA & زيارة مسائية ( .,0-11 مساءl) \\
\hline$\% 1 \ldots$ & $1 v \varepsilon$ & الإجمالي \\
\hline
\end{tabular}

المصدر : من عمل الباحثة اعتمادا على تحليل استمارات الاستبيان.

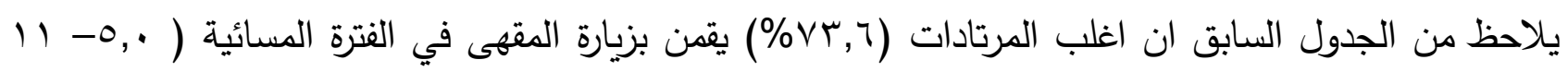

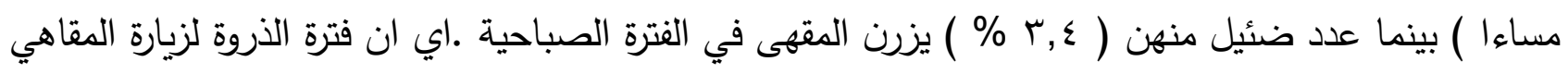

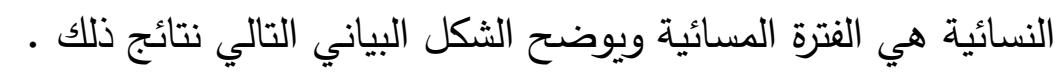
د-معدل الصرف في كل زيارة: ولدارسة معدل الصرف فى كل زيارة تم تفريخ نتائج استمارة الاستبيان فى جدول ( (Y ) كما يلى : 
جدول ( ا r ) مواعيد زيارة المقاهى للمترددات على المقاهى النسائية بمدينة خميس مشيط بالعينة

\begin{tabular}{|c|c|c|}
\hline الانحراف المعياري & متوسط معدل الصرف & اسم المقهى \\
\hline$\vee 0, .0$ & $1 \cdot V, V V$ & تيفاني \\
\hline$\wedge r, q \wedge$ & 109,0r & جلسة هادئة \\
\hline $07, \wedge \varepsilon$ & $11 \vee, 0$. & دايت كوفي \\
\hline$r v, 7 q$ & $V Y, V T$ & سنيون \\
\hline 07,11 & או,ו & سوفليه الواحة \\
\hline 10,11 & $\mid v \cdot, q 1$ & سيحة بال \\
\hline$v \leq, q$. & $111, r o$ & ماما روتى \\
\hline$V \varepsilon$, or & س & الإجمالي \\
\hline
\end{tabular}

المصدر : من عمل الباحثة اعتمادا على تحليل استمارات الاستبيان.

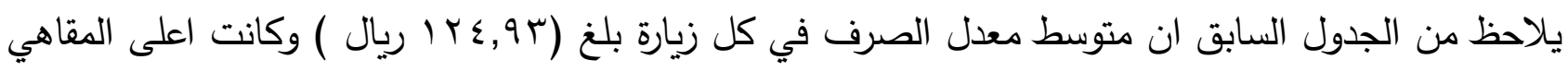

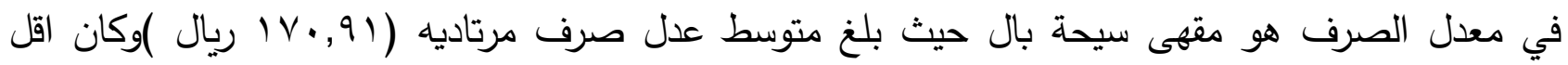

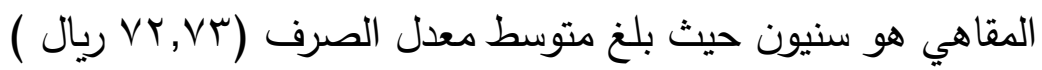
شكل ( 10 ) معدل الصرف لكل زيارة للمترددات على المقاهى النسائية بمدينة خميس مشيط بالعينة

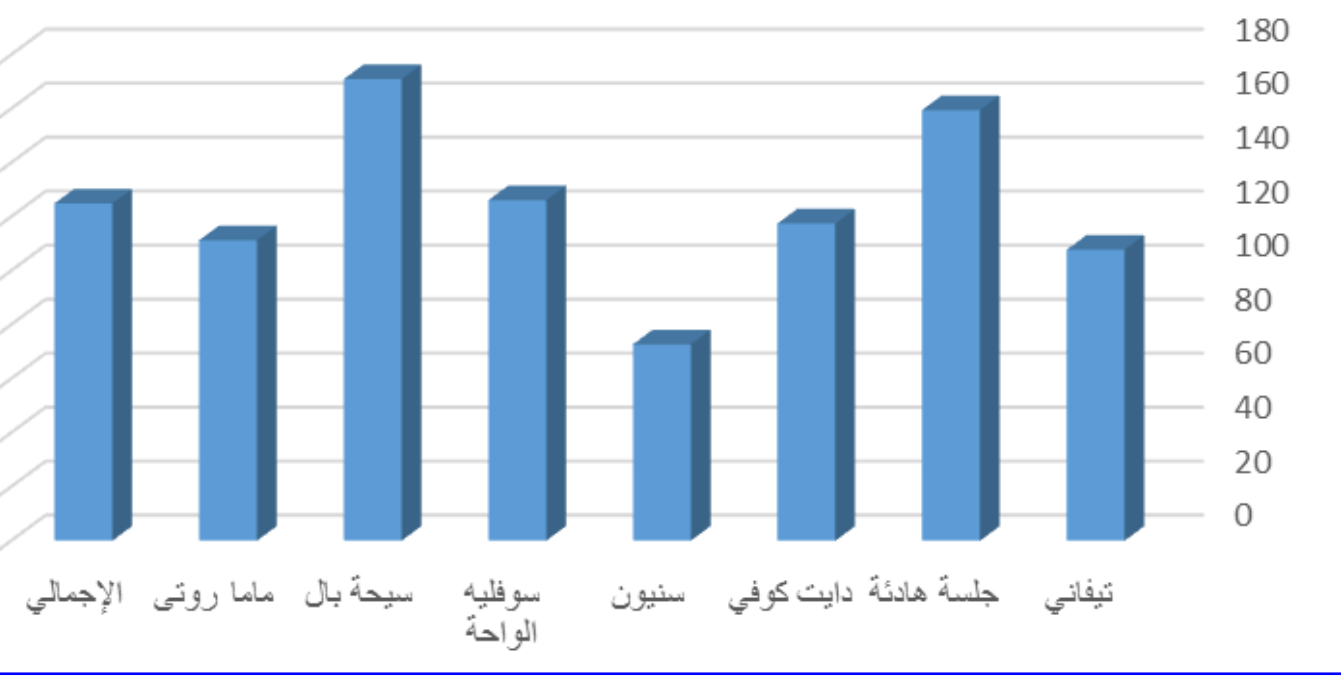

المصدر : من عمل الباحثة اعنمادا على بيانات جدول ( ( ) ) 


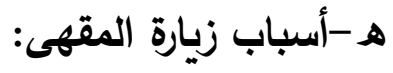
تتعدد اسباب زيارة المقاهى بين مقابله الصديقات او مقابله افراد العائله او الاستراحة او غير ذلك وكانت

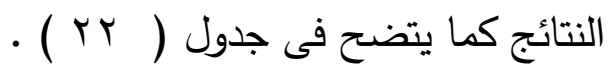
جدول (r ) مبب زيارة المقاهى للمترددات على المقاهى النسائية بمدينة خميس مشيط بالعينة

\begin{tabular}{|c|c|c|c|}
\hline النسبة المئوية & التكرار & سبب الزيارة & الترتيب \\
\hline$\% \curlyvee \varepsilon$ & $\wedge \wedge$ & مقابلة الصديقات & 1 \\
\hline$\% \backslash \leqslant, \vee$ & $0 \varepsilon$ & عدم وجود أماكن ترفيه أخرى & r \\
\hline$\% \backslash \leqslant, r$ & or & مكان لمقابلة افراد العائلة & $r$ \\
\hline$\% 1 \cdot, 1$ & rv & القضاء على أوقات الفراغ والملل & $\varepsilon$ \\
\hline$\% \vee, q$ & rq & تواجده داخل المجمع التجاري & ○ \\
\hline$\% \vee, \uparrow$ & rı & بهدف التجربة & 9 \\
\hline$\% \vee, \varepsilon$ & rv & الاستراحة بعد عناء التسوق & $v$ \\
\hline$\% \vee, 1$ & rт & الخروج من المنزل فقط & $\wedge$ \\
\hline$\% r, r$ & ir & تقليد الاخرين & 9 \\
\hline$\% r, r$ & $\wedge$ & لحل بعض المشاكل (عائلية -عمل) & 1. \\
\hline$\% 1,1$ & $\varepsilon$ & مكان لعقد اجتماع عمل او قضاء مهمة & 11 \\
\hline$\% \cdot, r$ & 1 & اكتساب صداقات جديدة & ir \\
\hline$\% \cdot, r$ & 1 & مجاورته لمنشئات تجارية متعددة & ir \\
\hline
\end{tabular}

المصدر : من عمل الباحثة اعتمادا على تحليل استمارات الاستبيان.

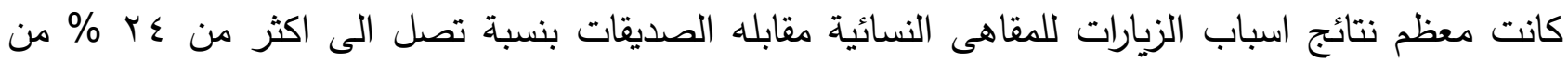
المترددات على المقاهى بينما كانت مقابله افراد من العائله وعدم وجود اماكن ترفية فى المرتبة الثانية بنسبة اكثر من عـ \% من المترددات على المقاهى وكانت اقل النسب وهى اكتساب صداقات جديدة بنسبة rr. \% من المترددات على المقاهى كما يلى : 
شكل ( 1 ( ) اسباب زيارة المترددات على المقاهى النسائية بمدينة خميس مثيط بالعينة

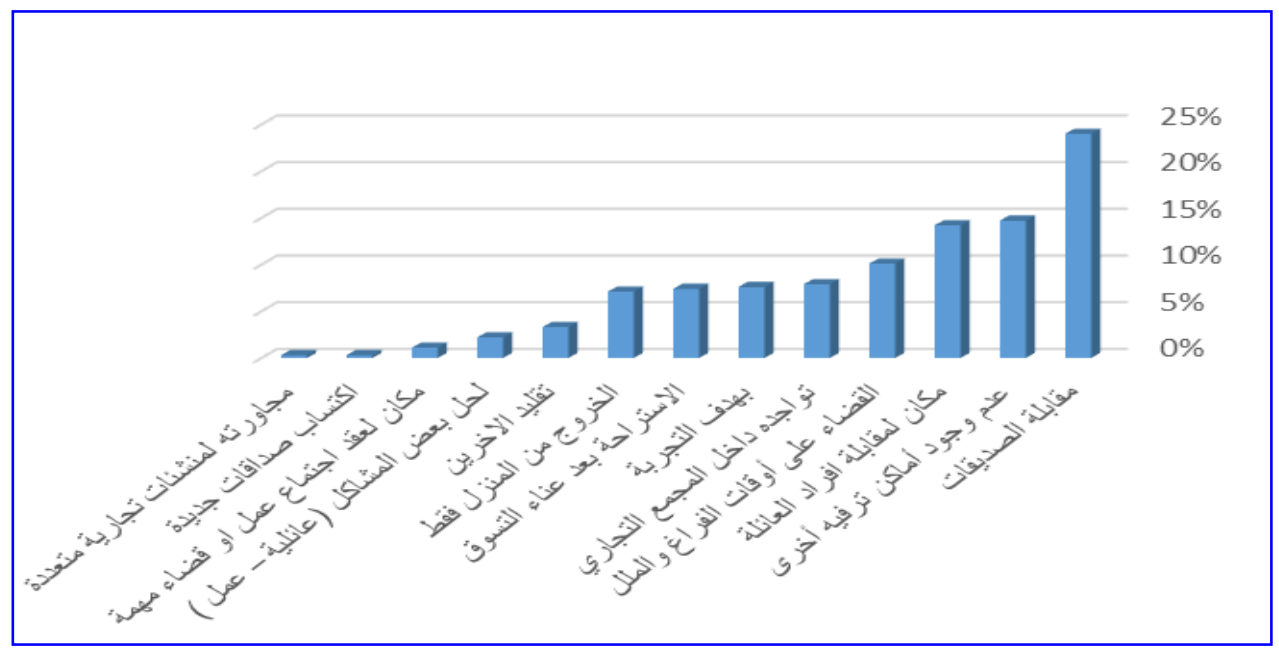

المصدر : من عمل الباحثة اعتمادا على بيانات جدول ( r )

و -أسباب تفضيل زيارة المقهى عن غيره من المقاهي: تتوعت طرق تفضيل المقاهى بعضها عن بعض وكانت النتائج كما يلى جدول (Tr ) سبب زيارة المقاهى للمترددات على المقاهى النسائية بمدينة خميس مشيط بالعينة

\begin{tabular}{|c|c|c|c|}
\hline النسبة المئويـة & التكرار & سبب التفضيل & الترتيب \\
\hline$\%$ \%ч, & 1) & | الرغبة الشخصية & 1 \\
\hline$\%$ \%ч, & 1) & جودة ونوعية الطلبات في المقهى & r \\
\hline$\% 10, r$ & $\varepsilon V$ & موقع المقهى الجيد وسهولة الوصول اليه & r \\
\hline$\% 11$ & $r \varepsilon$ & الأسعار المناسبة في المقهى & $\varepsilon$ \\
\hline$\% \wedge, \varepsilon$ & $r t$ & الجو العام للمقهى & $\bullet$ \\
\hline$\% 0, r$ & 17 & الشعور بالراحة النفسية داخل المقهى & 7 \\
\hline$\% r, q$ & 9 & الوضع الوظيفي & v \\
\hline$\% r, r$ & v & الخدمات المتوفرة في المقهى & $\wedge$ \\
\hline$\% 1,7$ & 0 & وجود هيئة اشرافيه على المقهى & 9 \\
\hline$\% \cdot, 7$ & r & | وجود وسائل الترفيه بالمقهى & 1. \\
\hline
\end{tabular}

المصدر : من عمل الباحثة اعتمادا على تحليل استمارات الاستبيان. 


$$
\text { حنان عبد الهادي سعيد القاضي القحطاني }
$$

$\vee \varepsilon$.

احتلت الرغبة الثخصية المرتبة الاولى فى تفضيل احد المقاهى عن الاخرى بنسبة اكثر من بr \% من جمله المترددات على المقاهى وناظرتها فى هذه النتيجة جودة ونوعية الطلبات فى المقاهى بنفس النسبة وايضا كان لموقع المقهى دور مهم فى عملية التفضيل حيث احتلت نحو ب, 10 \% من جمله المترددات على المقاهى ،

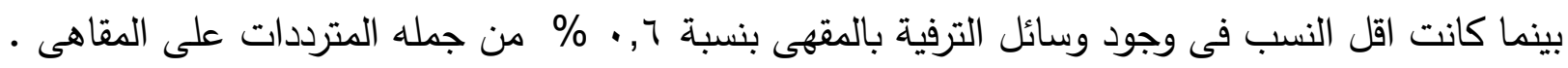
ز -الأنشطة التي تمارس في المقهى: تنوعت الانشطة التى تمارسها المترددات على المقاهى النسائية بمدينة خميس مشيط كما يتضح من الجدول التالى :

جدول ( ؟ ) نوع الانثطة التى تمارسها المترددات على المقاهى النسائية بمدينة خميس مشيط بالعينة

\begin{tabular}{|c|c|c|}
\hline النسبة المئوية & التكرار & الانثطة \\
\hline$\% \vee, 1$ & 。 & مشاهدة القنوات الفضائية \\
\hline$\%\{\wedge, \uparrow$ & $r \varepsilon$ & الانترنت \\
\hline$\% \backslash r, q$ & 9 & قراءة الصحف والمجلات \\
\hline \%ऑ।, ₹ & rr & أنثطة أخرى \\
\hline
\end{tabular}

المصدر: من عمل الباحثة اعتمادا على تحليل استمارات الاستبيان.

يلاحظ من الجدول السابق ان اكثر الأنشطة ممارسة داخل المقهى هو نشاط الانترنت واقل الأنشطة هو مشاهدة

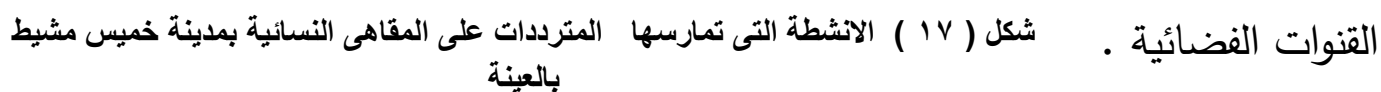

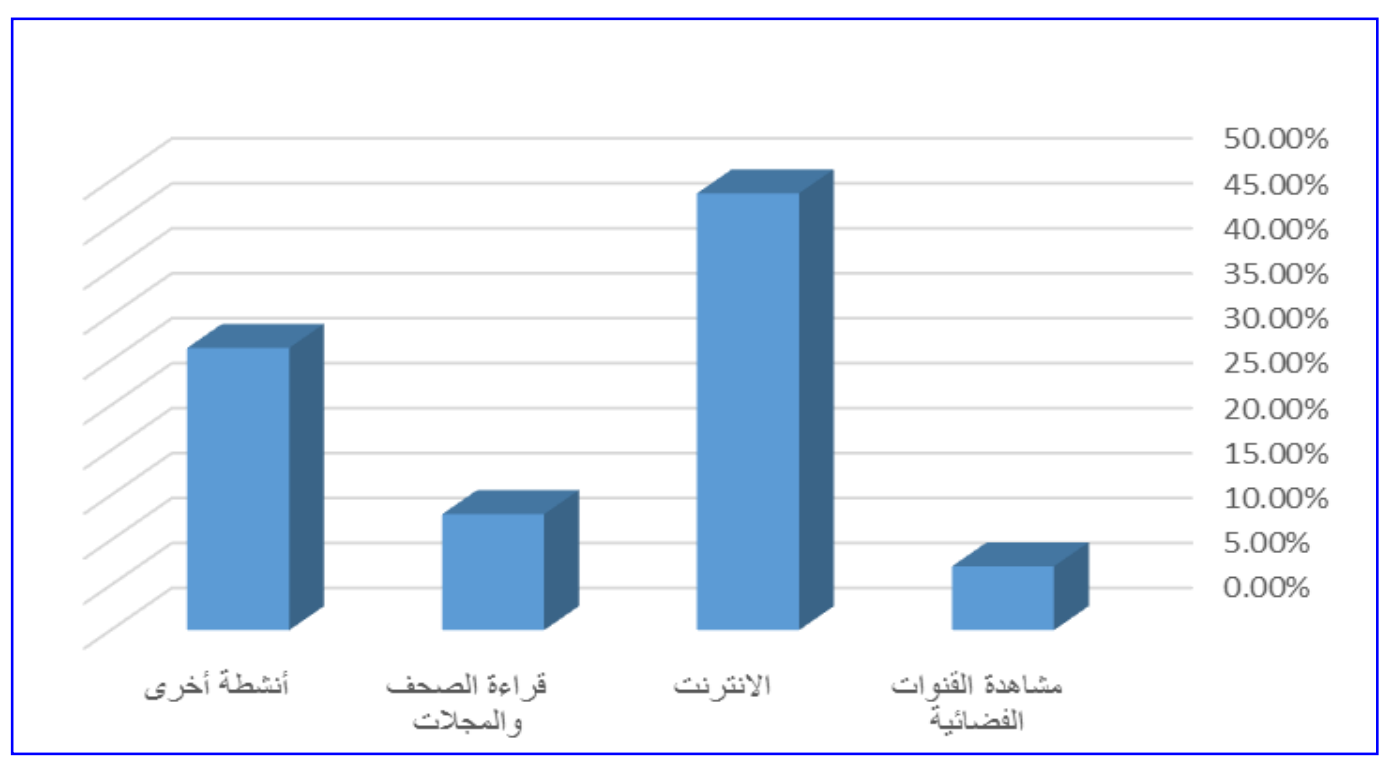

المصدر : من عمل الباحثة اعتمادا على بيانات جدول ( ع ) ) 
ح- وجود وسائل او أماكن بديلة للترفيه:

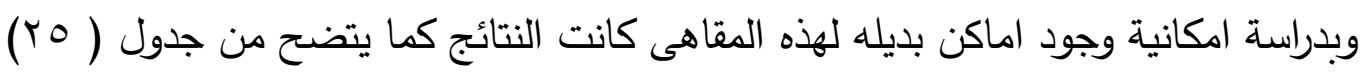
جدول (ro ) نوع الانثطة التى تمارسها المترددات على المقاهى النسائية بمدينة خميس مشيط بالعينة

\begin{tabular}{|c|c|c|}
\hline النسبة المئوية & التكرار & مدى وجود وسائل او أماكن بديلة \\
\hline$\% r v, r$ & $T$ & توجد \\
\hline$\%$ \% r, & 1.1 & لا توجد \\
\hline
\end{tabular}

المصدر: من عمل الباحثة اعتمادا على تحليل استمارات الاستبيان.

اقر غالبية افراد العينة (1, بآ) بعدم وجود أماكن بديلة او وسائل غير المقاهي للترفيه

9- الأماكن البديلة تسد احتياجاتهم في الترفيه :

جدول (Tr ) افضلية الاماكن البديله المترددات على المقاهى النسائية بمدينة خميس مشيط بالعينة

\begin{tabular}{|c|c|c|}
\hline النسبة المئوية & التكرار & هل الأماكن البديلة تسد احتياجاتهم في الترفيه \\
\hline$\% r v, 1$ & TY & نعم \\
\hline$\%$ \%r,q & 1.0 & ע \\
\hline
\end{tabular}

المصدر : من عمل الباحثة اعتمادا على تحليل استمارات الاستبيان.

اقر غالبية افراد العينة (9,9 T) بان الأماكن البديلة لا تسد احتياجاتهم في الترفيه ط -الصعوبات التي تواجهن في المقاهي:

لاسرة المشكلات التى توجه المترددات على المقاهى النسائية كانت النتائج كما يتضح من جدول ( TV ) جدول (rV ) الصعوبات التى تواجهن المترددات على المقاهى النسائية بمدينة خميس مشيط بالعينة

\begin{tabular}{|c|c|c|c|}
\hline النسبة المئوية & 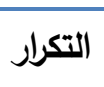 & الصعوبة & 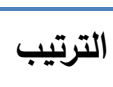 \\
\hline$\%$ \% & ov & وسيلة الترفيه الوحيدة في المكان & 1 \\
\hline$\% \backslash \wedge, \wedge$ & 01 & قلة عد المقاهي في المدينة & r \\
\hline$\% \backslash \leqslant, r$ & rq & عدم توفر الخدمات في المقهى & $r$ \\
\hline$\% 1 \cdot, v$ & rq & ارتفاع أسعار الطلبات في المقهى & $\varepsilon$ \\
\hline$\% \vee, \vee$ & ri & عدم توفر الطلبات للمترددات & ○ \\
\hline$\% 0,9$ & 17 & المكان المكشوف & 7 \\
\hline$\% \varepsilon, \wedge$ & 14 & الازعاج لوجود المقهى داخل مجمع تجارى & $v$ \\
\hline
\end{tabular}




\begin{tabular}{|c|c|c|c|}
\hline$\% \varepsilon$ & 11 & ضيق مكان المقهى & $\wedge$ \\
\hline$\%$ \% & 9 & انخفاض مستوى الدخل للمتردد & 9 \\
\hline$\% r, q$ & $\wedge$ & بعد المقهى وصعوبة الوصول اليه & 1. \\
\hline$\% r, r$ & 7 & عدم جودة الطلبات المقدمة في المقهى & 11 \\
\hline$\% r, r$ & 7 & الاختلاط & ir \\
\hline$\% 1,00$ & $\varepsilon$ & الازدحام في المقهى & ir \\
\hline$\% \cdot, \vee$ & r & 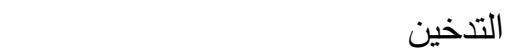 & $1 \varepsilon$ \\
\hline
\end{tabular}

الهصدر: من عمل الباحثة اعتمادا على تحليل استمارات الاستبيان.

مستوى (1 +,.•) بين العمر وعدد مرات زيارة المقهى

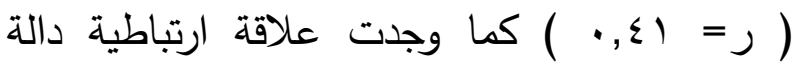

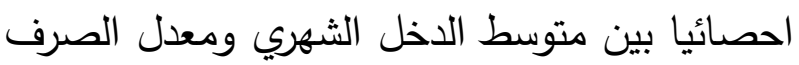

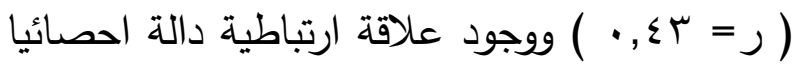
عند مستوى (1 (,.•) بين عدد مرات زيارة المقهى

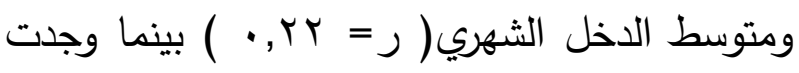
علاقة ارتباطية دالة احصائيا عند مستوى (1. (., )

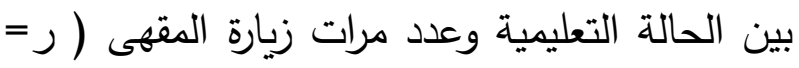
ما وجودت علاقة ارتباطية دالة احصائيا عند مستوى (1.,., بين المسافة بين مكان الإقامة

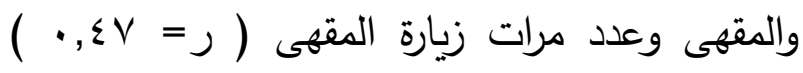
وايضا وجود علاقة وجود علاقة ارتباطية دالة احصائيا عند مستوى (1 (.,.) بين موقع السكن

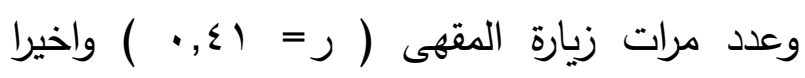
وجدت علاقة ارتباطية دالة احصائيا عند مستوى

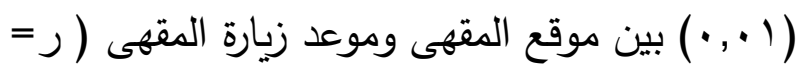

$$
\cdot(\cdot, r q
$$
تعد المقاهى هى وسيله الترفيه الوحيدة فى المكان

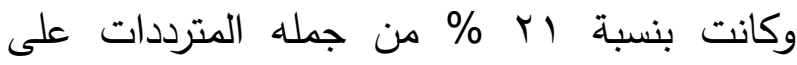
المقاهى وكذلك كانت مشكله قله عدد المقاهى فى المدينة ايضا بنسبة اكثر من \| 1 \% من جمله

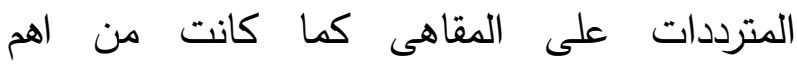
المشكلات عدم وجود خدمات فى المقهى بنسبة

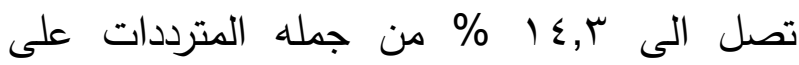
المقاهى بينما كانت اقل المشاكل فى هذه المقاهى هى التدخين بنسبة V,, • من جمله المترددات على المقاهى والاختلاط بنسبة ر, 1 \% من جمله

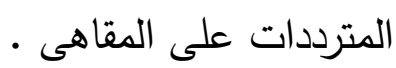
ي - علاقات الارتباط بين الخصائص المميزة لمترددات على المقاهى .

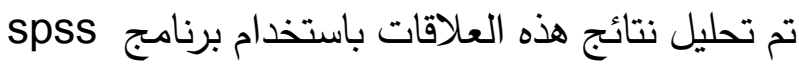

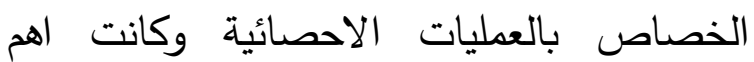
النتائج وجود علاقة ارتباطية دالة احصائيا عند مستوى (1., •) بين موقع السكن والمسافة بين

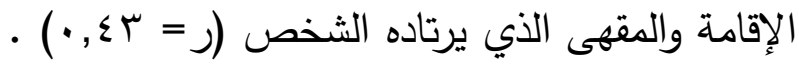
وكذلك وجود علاقة ارتباطية دالة احصائيا عند الاندان 
- العمل على زيادة هذه المقاهى من خلال زيادة القروض وكذلك تقديم التسهيلات اللازمة لذلك او انشاء مقاهى نسائية حكومية . - متابعة ومراقبة هذه المقاهى والحث على تواجد اماكن مخصصة لرعاية الاطفال فى تلك المقاهى . - مراقبة الاسعار فى تلك المقاهى والعمل على توافر جميع الخدمات بها - زيادة الايدى العامله وعمل شاشات عرض للشباب فى المقاهى النسائية . المراجـع والمصادر

اولا المراجع العربية : - أبو صبحة ، كايد عثمان ، (Y (Y. (Y) جغرافية المدن دار وائل للطباعة والنشر ، عمان .

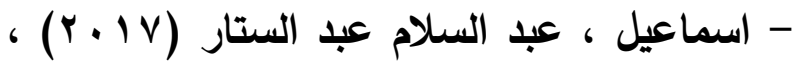
التحليل المكاني للخدمات المصرفية بمدينة بورسعيد دراسة في جغرافية الإتصالات،الجمعية الجغرافية المصريـة.

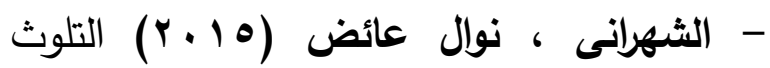
الضوضائي في مدينة خميس مشيط ، رساله ماجستير منشورة ، كلية العلوم الانسانية، جامعة الملك خالد ، المملكة العربية السعودية .

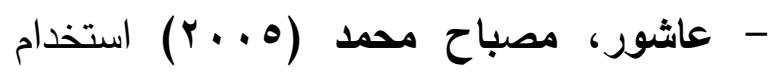
تقنيات نظم الدعلومات الجغرافية والاستشعار عن بعد في تحديد محاور التوسع العمراني في مدينة
اولا: النتائج : - لعب العوامل الجغرافية دورا كبيرا فى التوزبع الجغرافى للمقاهى النسائية بمدينة خميس مشيط حيث تركز معظم هذه المقاهى فى احياء مركز المدينة ذات الكثافة العالية فى عدد السكان وذات الاستخدام التجارى والصناعى المميز بتلك المنطقة . - اظهرت نتائج استمارات الاستبيان ان عامل المسافة وزمن الوصول لهذه المقاهى له دور مهم فى عدد مرات التردد وذلك كونها تتتاسب عكسيا مع بعد المسافة وان كان متوسط البعد يصل الى نحو بr كم وهى تعتبر مسافة جيدة . - كما كانت معظم المترددات على هذه المقاهى من الجنسية السعودية ومن الطلبة الجامعيين التى تتراوح اعمارهم ما يقارب العشرون عاما . - واتضح من خلال تحليل النتائج ان معظم المترددات على هذه المقاهى هن العزباوات التى تسكن مع الاسر ومتوسط افراد هذه الاسر ما بين

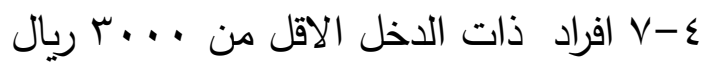
- كما تباينت الصعوبات التى تواجه المترددات على هذه المقاهى ومنها قله عدد هذه المقاهى ونقص الخدمات فى بعض الاماكن فضلا عن عدم وجود مناطق مخصصة لرعاية الاطفال بهذه المقاهى وان كانت اقل هذه الصعاب التدخين والاختلاط وذلك لتماسك المجتمع والمحافظة على العادات والتقاليد . 
الجغرافية ،ادارة الدراسات العمرانية ـ شروع المخطط الاقليمى لمنطقة عسير ، الرياض •

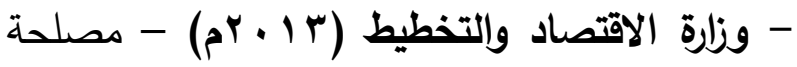
الإحصاءات العامة والمعلومات .

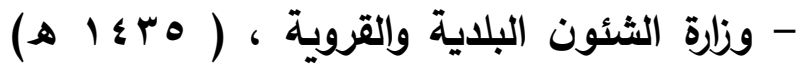
دليل المعايير التخطيطة للخدمات ، الرياض ، المملكة العربية السعودية .

\section{ثالثا : المراجع الاجنبية :}

- Al Sahili, K and Aboul-Ela, (1992) Accessibility of bublic services as on in dicator of from sportation system sustu in ability the case of irbid Jordan, journal of urban planning \& Development, Asce, vol 118.
مصراتة ، رساله ماجستير منشورة ، كلية الدراسات العليا جامعة V اكتوبر ، ليبيا .

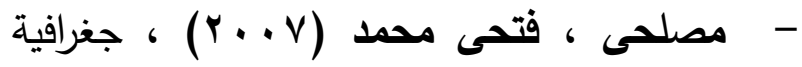
الخدمات، الإطار النظرى وتجارب عملية، دار

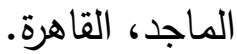
ثانيا : المصاد:

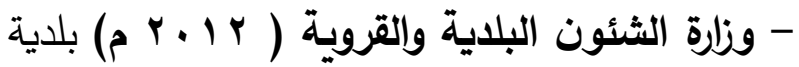
محافظة خميس مشيط ، وحدة نظم المعلومات - Bradford, M.G., Human

(1977) Geography, Oxford Univ. Press, London. رابعا المواقع الاكترونية : https://albukhari.com 18/8/2019 . http://www.aleqt.com 15/8/2019 


\title{
Geographical Characteristics of Women's Cafes in Khamis Mushayt City (Study in Economic Geography)
}

\author{
Hanan Al-Qahtani
}

This study focused on the geographical characteristics of women's cafes in Khamis Mushayt City, the study was divided into two sections, the first part is concerned with the geographical characteristics of women's cafes. These cafes affect a range of geographical factors such as geographical distribution and population density. The second part also studied the characteristics of women visiting these cafes in terms of the distance between the house and cafes, as well as the marital status, educational status, age structure and economic level. The problems of women in these cafes were also discussed. The most important of these difficulties was the lack of areas for children in these cafes as well as prices are expensive and some recommendations have been made to maintain the efficiency of these cafes, such as helping the owners of these cafes. 